\title{
Immunomodulating Efficacy of Different Adjuvants in Formulation of Foot and Mouth Disease Vaccine Relative to Its Immunogenicity
}

\author{
El-Sayed, E. I. *; Mossad, W.G.;Hassanin A. I. and Shabana, W.
}

Department of FMD, Veterinary Serum and Vaccine Research Institute (VSVRI), Abbasia, Cairo, Egypt.

*Corresponding Author, Ehab EL-Sayed Ibrahim, E-mail: ehabelsayed@ hotmail.com

\begin{abstract}
The ideal adjuvant is one that able to aid in early stimulation of the humeral immune response, and to promote the production of high antibody titers that would persist for long duration as well as stimulate the cellular immune response. This immunological study was conducted to reveal the aluminum hydroxide gel effect with the use of oil adjuvants on the immune response of polyvalent foot and mouth disease (FMD) vaccine in sheep. Twenty five sheep, were divided to five group (five animals/group) where the $1^{\text {st }}$ group was vaccinated with polyvalent FMD ISA 206 oil vaccine, $2^{\text {nd }}$ group was vaccinated with polyvalent FMD ISA 206 + aluminum hydroxide gel vaccine, $3^{\text {rd }}$ group was vaccinated with polyvalent ISA 201 oil vaccine, $4^{\text {th }}$ group was vaccinated with polyvalent ISA $201+$ aluminum hydroxide gel vaccine, $5^{\text {th }}$ group was kept as a negative control (non-vaccinated). Blood and Serum samples were collected from vaccinated animals for monitoring the cellular and humeral immune responses. The results showed that sheep groups immunized with the vaccine prepared with ISA 201with aluminum hydroxide gel is considered the best cellular and humeral immunity post vaccinal response then ISA 201 followed by ISA 206 with aluminum hydroxide gel and the last one is the vaccine prepared with ISA 206 alone.It can be concluded that, ISA oils with aluminum hydroxide gel induce the best cellular and humeral immunity.
\end{abstract}

Keywords: Aluminum hydroxide gel, FMD vaccine, immune response, Montanide ISA201, Montanide ISA206.

J. Appl. Vet. Sci., 5(3 ): 14-30.
Original Article:

DOI:HTTPS://DX.DOI.ORG/10.21608/JAV $\underline{2020.98318}$

Received :21 April, 2020.

Accepted :02 June, 2020.

Published in:July, 2020.

This is an open access article under the term of the Creative Commons Attribution 4.0 (CC-BY) Internationa License. To view a copy of this license visit

http://creativecommons.org/licenses/by/ $\underline{4.0 /}$

\section{INTRODUCTION}

Foot and Mouth disease (FMD) is a highly infectious disease of ungulates primarily cattle, sheep, goats and pigs. It also affects wild animals such as buffalo and deer (Paton et al., 2009 and Dara et al., 2013). Foot and Mouth disease virus (FMDV) is the etiologic agent of such devastating disease. Infection with FMDV causes an acute disease that spreads very rapidly and is characterized by fever, lameness, vesicular lesions on the feet, tongue, snout and teats, with high morbidity but low mortality (Depa et al, 2012 and Juleff et al., 2012). Seven types of FMDV have been identified such as O, A, C, SAT1, SAT2, SAT3 and Asia1 (Franki et al., 1991 and OIE, 2017).
Foot and Mouth disease (FMD) is enzootic in Egypt since 1950; it remains a serious threat to cattle and buffaloes population (Depa et al., 2012; Pattnaik et al., 2012 and Abd El-Rhman et al., 2015). Serotype $O$ has a long history in Egypt with many topotypes and lineages, serotype A was reported in 2006 followed by SAT2 serotype in 2012, (Sobhy et al., 2014; Valdazo et al., 2015 and Soltan et al., 2017). In Egypt, outbreaks have been reported since 1950, 1960, 2006, 2012 and 2018 for Serotype O (Farag et al., 2005 and Satya, 2009). Serotype A from live animals importation where sever clinical signs were recorded among cattle and buffaloes (Abd El-Rahman et al., 2006). Serotype SAT2/2012 was recorded in Egypt (Shawky et al., 2013 and Nader et al., 2014) and SAT2/2018 (Abd El-Rhman et al., 2020). 
Vaccination is a major tool for FMD control to mitigate the impact of clinical disease, or to reduce and eventually eliminate virus circulation as outlined in the Progressive Control Pathway for FMD (Food and Agriculture Organization, 2011).

The prevention strategy to avoid FMD outbreaks occurrence in Egypt is vaccination using locally produced (O Panasia-2\&A Iran-05\&SAT2/ EGY-2012) trivalent inactivated vaccine (El-Bagoury et al., 2014). Recently vaccination in Egypt was done using polyvalent inactivated FMD vaccine after field isolation of SAT2/EGY/2018 as typing of field circulated virus. Detection of the causative agent and preparation of vaccine against it was regarded as a necessity to adjunct disease control (Longjam $\boldsymbol{e t}$ al., 2011).

At present, no effective treatment is available for FMDV infected livestock, vaccination against FMD is the best option to prevent and control this disease. The inactivated vaccine has made significant contributions to prevent and control FMD since the 1990s. However, the potential risk of the virus escaping from the vaccinated herd may cause the spread of the disease (Rodriguez and Grubman, 2009).

Adjuvant is a substance added to vaccine to improve the immunogenicity of antigens, and it can induce stronger immune responses and reduce the dosage and production cost of vaccine in populations responding poorly to vaccination. Adjuvants increase either humeral or cell-mediated immune response (Barnett et al., 2003; Lombard et al., 2007 and Park, 2013). Adjuvants in development or in use mainly include aluminum salts, oil emulsions, saponins, immune-stimulating complexes, liposomes, microparticles, nonionic block copolymers, polysaccharides, cytokines, and bacterial derivatives.

The oil adjuvant has the capability for generating a rapid, high, long-lasting immune response. Generally, the Montanide series of oil adjuvants (SEPPIC, France) has a clear immunological effect for inactivated vaccine in different susceptible animals (Fakhry et al., 2012; Dara et al., 2013and El-Sayed et al., 2015). Recently, SEPPIC has developed a new adjuvants (Montanide ISA-201 and Montanide ISA-
206) and claimed that those adjuvants induce better immune responses (particularly CMI responses).

Inactivated FMD vaccines are commonly produced as gel or oil adjuvants. Vaccines containing aluminum hydroxide and saponin as adjuvants have several disadvantages such as the induction of shortlived antibody responses which require relatively frequent revaccinations at intervals of 6 or even 4 months. In contrast, oil-based adjuvant FMD vaccines appear to have several advantages such as the induction of high titers and long-lived antibody responses, resulting in more effective protection (Aucouturier $\boldsymbol{e} t$ al., 2001 and Cloete et al., 2008).

In studies of vaccine developments for FMD, it is desirable that the adjuvants are applied directly to susceptible target animals. In this study the effects of experimental vaccines using various kinds of adjuvants were compared in sheep in order to achieve highly effective and potent vaccine in corresponding to onset and duration of the immune response of sheep against different targeted FMDV serotypes.

\section{MATERIALS AND METHODS}

\section{Animals \\ Sheep}

Twenty five breed native sheep, one year old and weighted between 55 and $60 \mathrm{~kg}$, were found to be free from FMD type O Pan Asia-2, A Iran O5, SAT2/Egypt /2012 and SAT2/Egypt /2018 antibodies as screened by serum neutralization test (SNT) and divided into five groups, (five animals/group) as follow:

- Group-1 (GP1) vaccinated with polyvalent FMD vaccine adjuvant with ISA 206 oil

- Group-2 (GP2) vaccinated with polyvalent vaccine adjuvant with FMD ISA 206 and aluminum hydroxide gel

- Group-3 (GP3) vaccinated with polyvalent FMD vaccine adjuvant with ISA 201 oil

- Group-4 (GP4) vaccinated with polyvalent FMD vaccine adjuvant with ISA 201 and aluminum hydroxide gel

- Group-5 (GP5) was kept non-vaccinated as negative control . 


\section{Suckling baby mice}

Fifty suckling Albino Swiss baby mice, 2-4 days old, (Charles River Strain, USA) were supplied by laboratory animal Department, Veterinary Serum and Vaccine Research Institute (VSVRI), Abbasia, Cairo, were used for the safety testing of complete virus inactivation.

\section{Samples}

Heparinized blood samples were obtained from vaccinated and control non vaccinated animals at 0,3 , 7, 14, 21 and 28 days post vaccination for detecting cellular immune response of vaccinated sheep by determination of Lymphocyte blastogenesis using cell proliferation kit (XTT kit), phagocytic percentage, phagocytic index, and interleukine-6.

Also, serum samples were obtained from blood samples collected weekly post vaccination (WPV) for one month and then every 2 WPV up to 4 months and finally each 4 WPV till the end of the experiment (40WPV) to follow up the humeral antibody response of vaccinated sheep using SNT and enzymes linked immunoadsorbent assay (ELISA).

\section{Cell culture}

Baby Hamster kidney cell line (BHK21) Clone 13 was obtained from veterinary serum and vaccine research institute (VSVRI) using Eagl's medium with $8-10 \%$ bovine serum as described by (Xuan et al., 2011) and used for application of SNT, virus titration and vaccine preparation.

\section{FMD virus Serotypes}

Egyptian isolated FMDV Serotypes O Pan Asia2, A Iran O5, SAT2/Egypt /2012 and SAT2/Egypt /2018 with a titer $10^{9} \mathrm{TCID}_{50} / \mathrm{ml}$ for each type were supplied by Foot and Mouth Vaccine Research Department (FMDRD), VSVRI, Abbasia, Cairo. The virus Serotype O, A and SAT-2 were confirmed by the World Reference Laboratory for FMD (WRL), Pirbright London, UK. These viruses were used in vaccine preparation and serum neutralization test (SNT).

\section{Adjuvants}

Montanide ISA206: Montanide ISA 206 was obtained from Seppic, Paris, France.

Montanide ISA201: Montanide ISA 201 was obtained from Seppic, Paris, France.
Aluminum hydroxide gel: $2.5 \%$ aluminum hydroxide gel was prepared as an alum-based adjuvant. (Patil $\boldsymbol{e t}$ al., 2002a)

\section{Virus purification}

Aseptically, the harvested culture media from FMD virus infected BHK21 cell cultures were centrifuged in a cooling centrifuge at $3000 \mathrm{rpm}$ for 20 min. to remove cell debris.

\section{Virus concentration}

The tissue culture viral fluids of the three serotypes of FMDV (O pan Asia, A Iran O5, SAT2/EGY/2012 and SAT2/EGY/2018) were centrifuged at 7000 round per minute RPM for $30 \mathrm{~min}$ and then concentrated by Poly Ethylene Glycol (PEG)6000 to reach $1 / 10$ of its original volume (Shabana, 2014).

\section{Virus inactivation}

Binary ethylenamine (BEI) $1 \% \mathrm{M}$ in $0.2 \mathrm{~N}$ $\mathrm{NaOH}$ was added to the virus suspension to give final concentration of $0.001 \mathrm{M}$ of BEI. The virus and BEI mixtures were mixed well. The virus mixture was placed on a magnetic stirrer in the incubator at $37^{\circ} \mathrm{C}$ for $18 \mathrm{~h}$.Then sodium thiosulphate was added in a final concentration of $2 \%$ to neutralize the BEI action according to (Ismail et al., 2013).

\section{Vaccine formulations}

Four vaccine formulae were prepared as follow:

Formula-1: Polyvalent FMD vaccine adjuvanted with Montanide ISA 206.

Formula-2: Polyvalent FMD vaccine adjuvanted with Montanide ISA 206 and aluminium hydroxide gel.

Formula-3: Polyvalent FMD vaccine adjuvanted with Montanide ISA 201.

Formula-4: Polyvalent FMD vaccine adjuvanted with Montanide ISA 201 and aluminium hydroxide gel.

The concentrated FMDV serotype O Pan Asia2, A Iran O5, SAT2/Egypt /2012 and SAT2/Egypt /2018 used were diluted using Tris $\mathrm{NaCl}$ with $\mathrm{pH}$ of 7.6 to be reached a final antigen content $3 \mu \mathrm{g} /$ dose from each serotypes of FMDV according to (Daoud et al., 2013) and then added to each adjuvant used. When we used Montanide ISA 206 and 201adjuvant, the vaccine was formulated according to (Barnett et al., 1996). The ratio of the aqueous antigen to the oil adjuvant was 50:50 
(w/w) according to (OIE 2017). In the oil/gel adjuvant mixture, $10 \%$ of Aluminum hydroxide (AL) was added according to (Park et al., 2016). The amount of antigen per dose of vaccine per serotype was maintained as the same amount of antigen was pre-diluted to the same concentration before mixing it with the target experimental adjuvants. The applied dose of all vaccine formula was $1.5 \mathrm{ml}$ inoculated subcutaneously in all experimental animals group.

\section{Quality control testing of the prepared vaccine formulae}

\section{Sterility test}

The prepared vaccines were tested for their freedom of aerobic and anaerobic bacteria, fungal and mycoplasma contaminants by cultured of vaccine sample in thioglycolate broth, Sabouraud's, Nutrient agar; phenol dextrose media and mycoplasma medium (OIE, 2017 and Code of Federal Regulation of USA, 2019).

\section{Safety test}

Complete virus inactivation was confirmed in five days Swiss Albino suckling mice according to (Randall et al., 1964).

\section{Potency test}

\section{Evaluation of the cellular immune response} Lymphocyte blastogenesis using XTT assay

Blood samples were collected from all sheep groups on the $1^{\text {st }} ; 3^{\text {rd }} ; 7^{\text {th }} ; 14^{\text {th }} ; 21^{\text {st }}$ and $28^{\text {th }}$ days postvaccination followed by separation of lymphocytes (Lucy, 1977 and Lee, 1984) and subjected to lymphocyte blastogenesis using XTT assay (Slater $\boldsymbol{e t}$ al., 1963 and EL-Naggar, 2012) and determination of viable cell number (Mayer et al., 1974).

\section{Separation and cultivation of mononuclear cells}

The preparation of mononuclear cell suspension was separated by Ficollhypaque equilibrium centrifugation method (Antley and Hazen, 1988) from sheep peripheral blood cell suspension was adjusted to $10^{7}$ viable mononuclear cells/ml RPMI medium containing 15\% Fetal Calf Serum and placed in cell culture 6-wells plate. The monolayer cells were rinsed 3 times gently with RPMI medium to remove non adherent cell. The adherent cells were then covered with RPMI medium containing $15 \% \quad$ FSC and incubated for 24 hours in $\mathrm{CO} 2$ incubator at $37^{\circ} \mathrm{C}$.
Phagocytic activity of sheep macrophages by using Candida Albicans

The monolayer of adherent mononuclear cells was washed gently 3 times with RPMI medium. Candida albicans cell suspension containing $10^{5} \mathrm{cell} / \mathrm{ml}$ RPMI medium was incubated with the above monolayers in humidified $\mathrm{CO} 2$ incubator at $37{ }^{\circ} \mathrm{C}$ for 1 hour. After incubation, the monolayer cells were washed gently with cold RPMI medium and then fixed with methyl alcohol $(0.3 \mathrm{ml} / \mathrm{well})$ for $5 \mathrm{~min}$. The alcohol was discarded and left to dry. The cells were stained with Giemsa stain for 3 minutes. Under the light microscope, using oil immersion lens, 10 fields were examined. The total numbers of phagocytic cells, the number of phagocytes ingested yeast cell and the number of blastospores within individual phagocyte were determined. The percentage of phagocytes containing blastospores was determined by the method of Harmon and Glisson which was modified by (Hussein 1989) and the mean number of blastospores (more than 2 blastospores) per infected phagocyte (phagocytic index) were calculated by (Richardson and Smith, 1981).

\section{Estimation of interleukin}

Estimation of the level of interleukin in the sera of vaccinated and control sheep including IL-6 levels was carried out using sheep IL-6 ELISA Kit Catalog No. EKE51028 supplied by Biomatik Company, Wilmington, Delaware, USA.

\section{Evaluation of sheep humeral immune response to the prepared vaccines in sheep}

Serum samples collected from sheep before and after vaccination (4 times on week intervals then every month up to 40 weeks) were subjected to estimation of antibody titers against the four serotypes of FMDV (O pan Asia, A Iran O5, SAT2/ EGY/2012 and SAT2/ EGY/2018) by SNT using the micro titer technique (Ferreira, 1976) and indirect ELISA (Voller et al., 1976).

\section{Statistical analysis}

Data were analyzed using analysis of variance (ANOVA) in the SPSS-12 statistical software package. Multiple comparisons of means were made using Duncan's multiple range tests at $\mathrm{P}<0.05 \%$.The results represent the average of five replicates and are presented as the mean \pm standard error. 


\section{RESULTS}

Table 1. Safety test results of the prepared polyvalent FMD vaccines

\begin{tabular}{|cccc|}
\hline \multicolumn{4}{|c|}{ Prepared Polyvalent FMD Vaccines } \\
\hline Formula-1 & Formula-2 & Formula-3 & Formula-4 \\
\hline Safe & Safe & Safe & Safe \\
\hline
\end{tabular}

Table 2. Mean delta optical density of lymphocyte blastogenesis assay in sheep vaccinated with the prepared FMD polyvalent vaccine formulae

\begin{tabular}{|cccccccc|}
\hline \multirow{2}{*}{ Vaccine formulae } & \multicolumn{6}{c|}{ Delta optical density of lymphocyte blastogenesis/ day post vaccination (DPV) } \\
\cline { 2 - 8 } & $1^{\text {st }}$ day & $3^{\text {rd }}$ day & $7^{\text {th }}$ day & $14^{\text {th }}$ day & $21^{\text {st }}$ day & $28^{\text {th }}$ day \\
\hline Formula-1 & 0.11 & 0.36 & 0.54 & 0.59 & 0.61 & 0.50 \\
\hline Formula-2 & 0.22 & 0.65 & 0.99 & 0.74 & 0.75 & 0.71 \\
\hline Formula-3 & 0.32 & 0.70 & 1.01 & 0.80 & 0.80 & 0.70 \\
\hline Formula-4 & 0.33 & 0.88 & 1.21 & 0.99 & 0.99 & 0.89 \\
\hline $\begin{array}{c}\text { Negative non } \\
\text { vaccinated control }\end{array}$ & 0.10 & 0.12 & 0.13 & 0.12 & 0.13 & 0.10 \\
\hline
\end{tabular}

Table 3. Phagocytic \% of sheep vaccinated with the prepared FMD polyvalent vaccine formulae

\begin{tabular}{|cccccccc|}
\hline \multirow{2}{*}{ Sheep groups } & \multicolumn{5}{c|}{ Phagocytic percentage } \\
\cline { 2 - 7 } & 1 day & $3^{\text {rd }}$ day & $7^{\text {th }}$ day & $14^{\text {th }}$ day & $21^{\text {st }}$ day & $28^{\text {th }}$ day \\
\hline Formula -1 & 20.1 & 30.2 & 49.7 & 56.1 & 66.4 & 54.2 \\
\hline Formula -2 & 23 & 33.2 & 53.8 & 69.2 & 66.2 & 63 \\
\hline Formula -3 & 23.3 & 34.2 & 55.1 & 70.4 & 66.3 & 64.2 \\
\hline Formula -4 & 29.2 & 37.5 & 81.2 & 92.3 & 70.4 & 60.1 \\
\hline Negative non vaccinated control & 19 & 19.5 & 19.4 & 19.5 & 19.5 & 19.4 \\
\hline
\end{tabular}

Table 4. Phagocytic index of sheep vaccinated with the prepared FMD polyvalent vaccine formulae

\begin{tabular}{|cccccccc|}
\hline \multirow{2}{*}{ Vaccine formulae } & \multicolumn{5}{c|}{ Phagocytic index } \\
\cline { 2 - 8 } & 1 day & $3^{\text {rd }}$ day & $7^{\text {th }}$ day & $14^{\text {th }}$ day & $21^{\text {st }}$ day & $28^{\text {th }}$ day \\
\hline Formula-1 & 0.11 & 0.32 & 0.49 & 0.61 & 0.69 & 0.45 \\
\hline Formula-2 & 0.10 & 0.50 & 0.61 & 0.82 & 0.8 & 0.58 & 0.59 \\
\hline Formula-3 & 0.10 & 0.50 & 0.67 & 0.84 & 0.81 & 0.90 & 0.68 \\
\hline Formula-4 & 0.11 & 0.84 & 0.98 & 0.99 & 0.12 & 0.10 \\
\hline Negative non vaccinated control & 0.12 & 0.12 & 0.12 & 0.13 & 0.12 & & \\
\hline
\end{tabular}

Table 5. Mean delta optical density of Interleukin-6 in sheep vaccinated with the prepared polyvalent FMD vaccine formulae

\begin{tabular}{|cccccccc|}
\hline \multirow{2}{*}{ Vaccine formulae } & \multicolumn{5}{c|}{ IL-6 (ng/ml) at DPV } \\
\cline { 2 - 8 } & 1 day & $3^{\text {rd }}$ day & $7^{\text {th }}$ day & $14^{\text {th }}$ day & $21^{\text {st }}$ day & $28^{\text {th }}$ day \\
\hline Formula-1 & 0.85 & 1.42 & 2.01 & 3.74 & 3.42 & 3.17 \\
\hline Formula-2 & 1.22 & 1.93 & 3.92 & 3.72 & 3.52 & 3.21 \\
\hline Formula-3 & 1.41 & 2.49 & 4.59 & 3.96 & 3.70 & 3.32 \\
\hline Formula-4 & 2.42 & 3.51 & 4.73 & 4.12 & 3.97 & 3.64 \\
\hline Negative non vaccinated control & 0.4 & 0.39 & 0.42 & 0.45 & 0.43 & 0.48 \\
\hline
\end{tabular}

Formula-1: Polyvalent FMD vaccine adjuvanted with Montanide ISA 206.

Formula-2: Polyvalent FMD vaccine adjuvanted with Montanide ISA 206 and aluminium hydroxide gel.

Formula-3: Polyvalent FMD vaccine adjuvanted with Montanide ISA 201.

Formula-4: Polyvalent FMD vaccine adjuvanted with Montanide ISA 201 and aluminium hydroxide gel. 


\section{El-Sayed, E. I. et al.....}

Table 6. FMD serotype-O serum neutralizing antibody titer and ELISA (expressed as $\log _{10}$ ) in different vaccinated sheep groups

\begin{tabular}{|c|c|c|c|c|c|c|c|c|}
\hline \multirow{4}{*}{ WPV } & \multicolumn{8}{|c|}{ Mean FMD serotype-O antibody titers in sheep vaccinated with } \\
\hline & \multicolumn{2}{|c|}{ Formula-1 } & \multicolumn{2}{|c|}{ Formula-2 } & \multicolumn{2}{|c|}{ Formula-3 } & \multicolumn{2}{|c|}{ Formula-4 } \\
\hline & SNT & ELISA & SNT & ELISA & SNT & ELISA & SNT & ELISA \\
\hline & $\pm \mathrm{SE}$ & $\pm \mathrm{SE}$ & $\pm \mathrm{SE}$ & $\pm \mathrm{SE}$ & $\pm \mathrm{SE}$ & $\pm \mathrm{SE}$ & $\pm \mathrm{SE}$ & $\pm \mathrm{SE}$ \\
\hline \multirow{2}{*}{0} & 0.27 & 0.42 & 0.3 & 0.6 & 0.3 & 0.6 & 0.3 & 0.6 \\
\hline & $\pm 0.15^{\mathrm{a}}$ & $\pm 0.19^{\mathrm{a}}$ & $\pm 0.088^{\mathrm{a}}$ & $\pm 0.102^{\mathrm{a}}$ & $\pm 0.12^{\mathrm{a}}$ & $\pm 0.03^{\mathrm{a}}$ & $\pm 0.047^{\mathrm{a}}$ & $\pm 0.043^{\mathrm{a}}$ \\
\hline \multirow{2}{*}{1} & 1.13 & 1.35 & 1.15 & 1.32 & 1.35 & 1.52 & 1.45 & 1.62 \\
\hline & $\pm 0.075^{\mathrm{a}, \mathrm{b}}$ & $\pm 0.01^{\mathrm{a}, \mathrm{b}}$ & $\pm 0.009^{\mathrm{a}}$ & $\pm 0.099^{\mathrm{a}}$ & $\pm 0.070^{\mathrm{a}, \mathrm{b}}$ & $\pm 0.14^{\mathrm{a}}$ & $\pm 0.077^{\mathrm{b}}$ & $\pm 0.077^{\mathrm{b}}$ \\
\hline \multirow{2}{*}{2} & 1.45 & 1.64 & 1.54 & 1.81 & 1.62 & 1.8 & 1.73 & 1.92 \\
\hline & $\pm 0.129^{\mathrm{a}}$ & $\pm 0.12^{\mathrm{a}}$ & $\pm 0.082^{\mathrm{a}}$ & $\pm 0.084^{\mathrm{a}}$ & $\pm 0.120^{\mathrm{a}}$ & $\pm 0.090^{\mathrm{a}}$ & $\pm 0.047^{\mathrm{a}}$ & $\pm 0.049^{\mathrm{a}}$ \\
\hline \multirow{2}{*}{3} & 1.65 & 1.92 & 1.72 & 1.96 & 1.74 & 2 & 1.86 & 2.21 \\
\hline & $\pm 0.070^{\mathrm{a}}$ & $\pm 0.090^{\mathrm{a}}$ & $\pm 0.095^{\mathrm{a}}$ & $\pm 0.104^{\mathrm{a}}$ & $\pm 0.070^{\mathrm{a}}$ & $\pm 0.070^{\mathrm{a}}$ & $\pm 0.037^{\mathrm{a}}$ & $\pm 0.045^{\mathrm{a}}$ \\
\hline \multirow{2}{*}{4} & 1.95 & 2.21 & 2.03 & 2.25 & 2.13 & 2.28 & 2.34 & 2.57 \\
\hline & $\pm 0.060^{\mathrm{b}}$ & $\pm 0.070^{\mathrm{b}}$ & $\pm 0.076^{\mathrm{a}}$ & $\pm 0.087^{\mathrm{a}}$ & $\pm 0.060^{\mathrm{b}}$ & $\pm 0.090^{\mathrm{b}}$ & $\pm 0.067^{\mathrm{a}}$ & $\pm 0.070^{\mathrm{a}}$ \\
\hline \multirow{2}{*}{6} & 2.42 & 2.63 & 2.5 & 2.81 & 2.55 & 2.87 & 2.72 & 2.98 \\
\hline & $\pm 0.090^{\mathrm{c}}$ & $\pm 0.090^{\mathrm{c}}$ & $\pm 0.006^{\mathrm{a}}$ & $\pm 0.075^{\mathrm{a}}$ & $\pm 0.090^{\mathrm{c}}$ & $\pm 0.040^{\mathrm{c}}$ & $\pm 0.122^{\mathrm{a}}$ & $\pm 0.128^{\mathrm{a}}$ \\
\hline \multirow{2}{*}{8} & 2.55 & 2.81 & 2.62 & 2.91 & 2.7 & 2.96 & 3.31 & 3.57 \\
\hline & $\pm 0.056^{\mathrm{b}}$ & $\pm 0.040^{\mathrm{b}}$ & $\pm 0.076^{\mathrm{a}}$ & $\pm 0.088^{\mathrm{a}}$ & $\pm 0.050^{\mathrm{b}}$ & $\pm 0.040^{\mathrm{b}}$ & $\pm 0.067^{\mathrm{a}, \mathrm{b}}$ & $\pm 0.075^{\mathrm{a}, \mathrm{b}}$ \\
\hline \multirow{2}{*}{10} & 2.58 & 2.83 & 2.92 & 3.13 & 3.1 & 3.23 & 3.28 & 3.48 \\
\hline & $\pm 0.056^{\mathrm{b}}$ & $\pm 0.040^{\mathrm{b}}$ & $\pm 0.006^{\mathrm{a}}$ & $\pm 0.03^{\mathrm{a}}$ & $\pm 0.050^{\mathrm{b}}$ & $\pm 0.050^{\mathrm{b}}$ & $\pm 0.095^{\mathrm{a}, \mathrm{b}}$ & $\pm 0.104^{\mathrm{a}, \mathrm{b}}$ \\
\hline \multirow{2}{*}{12} & 2.65 & 2.92 & 2.85 & 3.02 & 2.97 & 3.23 & 3.1 & 3.35 \\
\hline & $\pm 0.006^{\mathrm{b}}$ & $\pm 0.050^{\mathrm{b}}$ & $\pm 0.037^{\mathrm{a}}$ & $\pm 0.043^{\mathrm{a}}$ & $\pm 0.037^{\mathrm{c}}$ & $\pm 0.040^{\mathrm{c}}$ & $\pm 0.037^{\mathrm{b}}$ & $\pm 0.037^{\mathrm{b}}$ \\
\hline \multirow{2}{*}{14} & 2.76 & 2.99 & 2.79 & 2.99 & 2.85 & 3.11 & 2.93 & 3.2 \\
\hline & $\pm 0.030^{\mathrm{c}}$ & $\pm 0.030^{\mathrm{c}}$ & $\pm 0.006^{\mathrm{a}}$ & $\pm 0.056^{\mathrm{a}}$ & $\pm 0.050^{\mathrm{a}}$ & $\pm 0.050^{\mathrm{a}, \mathrm{b}}$ & $\pm 0.073^{\mathrm{b}}$ & $\pm 0.066^{\mathrm{b}}$ \\
\hline \multirow{2}{*}{16} & 2.46 & 2.69 & 2.52 & 2.71 & 2.67 & 2.93 & 2.83 & 3.08 \\
\hline & $\pm 0.050^{\mathrm{b}}$ & $\pm 0.040^{\mathrm{b}}$ & $\pm 0.10^{\mathrm{a}}$ & $\pm 0.101^{\mathrm{a}}$ & $\pm 0.06^{\mathrm{a}, \mathrm{b}}$ & $\pm 0.070^{\mathrm{a}, \mathrm{b}}$ & $\pm 0.082^{\mathrm{a}}$ & $\pm 0.074^{\mathrm{a}, \mathrm{b}}$ \\
\hline \multirow{2}{*}{20} & 2.12 & 2.45 & 2.22 & 2.31 & 2.46 & 2.72 & 2.62 & 2.9 \\
\hline & $\pm 0.060^{\mathrm{a}, \mathrm{b}}$ & $\pm 0.050^{\mathrm{a}, \mathrm{b}}$ & $\pm 0.102^{\mathrm{a}}$ & $\pm 0.095^{\mathrm{a}}$ & $\pm 0.080^{\mathrm{a}}$ & $\pm 0.090^{\mathrm{a}}$ & $\pm 0.073^{\mathrm{a}, \mathrm{b}}$ & $\pm 0.066^{\mathrm{a}, \mathrm{b}}$ \\
\hline \multirow{2}{*}{24} & 1.84 & 2.12 & 1.89 & 2.12 & 2.25 & 2.51 & 2.46 & 2.72 \\
\hline & $\pm 0.080^{\mathrm{a}}$ & $\pm 0.070^{\mathrm{a}}$ & $\pm 0.110^{\mathrm{a}}$ & $\pm 0.099^{\mathrm{a}}$ & $\pm 0.102^{\mathrm{a}, \mathrm{b}}$ & $\pm 0.115^{\mathrm{a}}$ & $\pm 0.076^{\mathrm{a}, \mathrm{b}}$ & $\pm 0.066^{\mathrm{a}, \mathrm{b}}$ \\
\hline \multirow{2}{*}{28} & 1.65 & 1.93 & 1.67 & 1.96 & 1.95 & 2.17 & 2.19 & 2.47 \\
\hline & $\pm 0.010^{\mathrm{a}, \mathrm{b}}$ & $\pm 0.093^{\mathrm{a}, \mathrm{b}}$ & $\pm 0.009^{\mathrm{a}}$ & $\pm 0.088^{\mathrm{a}}$ & $\pm 0.122^{\mathrm{b}}$ & $\pm 0.040^{\mathrm{b}, \mathrm{c}}$ & $\pm 0.142^{\mathrm{b}}$ & $\pm 0.144^{\mathrm{b}}$ \\
\hline \multirow{2}{*}{32} & 1.52 & 1.84 & 1.52 & 1.84 & 1.83 & 2 & 1.81 & 1.98 \\
\hline & $\pm 0.120^{\mathrm{b}, \mathrm{c}}$ & $\pm 0.118^{\mathrm{b}, \mathrm{c}}$ & $\pm 0.095^{\mathrm{a}}$ & $\pm 0.103^{\mathrm{a}}$ & $\pm 0.050^{c}$ & $\pm 0.07^{\mathrm{c}}$ & $\pm 0.056^{\mathrm{b}}$ & $\pm 0.058^{\mathrm{b}}$ \\
\hline \multirow{2}{*}{36} & 1.05 & 1.28 & 1.05 & 1.28 & 1.65 & 1.91 & 1.65 & 1.92 \\
\hline & $\pm 0.102^{\mathrm{a}, \mathrm{c}}$ & $\pm 0.047^{\mathrm{a}, \mathrm{c}}$ & $\pm 0.076^{\mathrm{a}}$ & $\pm 0.081^{\mathrm{a}}$ & $\pm 0.080^{\mathrm{b}}$ & $\pm 0.086^{\mathrm{b}}$ & $\pm 0.047^{\mathrm{a}, \mathrm{b}}$ & $\pm 0.043^{\mathrm{b}}$ \\
\hline \multirow{2}{*}{40} & 0.75 & 1.01 & 0.75 & 1.01 & 1.35 & 1.61 & 1.37 & 1.68 \\
\hline & $\pm 0.102^{\mathrm{a}, \mathrm{b}}$ & $\pm 0.086^{\mathrm{a}, \mathrm{b}}$ & $\pm 0.095^{\mathrm{a}}$ & $\pm 0.103^{\mathrm{a}}$ & $\pm 0.102^{\mathrm{a}}$ & $\pm 0.09^{\mathrm{a}, \mathrm{b}}$ & $\pm 0.076^{\mathrm{a}, \mathrm{b}}$ & $\pm 0.086^{\mathrm{a}}$ \\
\hline
\end{tabular}

SNT=Serum neutralization test, ELISA=Enzyme linked immune sorbent assay, WPV=Week post vaccination, SE=Standard error, FMDV=Foot and mouth disease virus, different letters indicate significant difference between different treatments at $\mathrm{p}<0.05$ according to Duncan's multiple range test 
Table 7. FMD serotype-A serum neutralizing antibody titer and ELISA (expressed as log10) in different vaccinated sheep groups

\begin{tabular}{|c|c|c|c|c|c|c|c|c|}
\hline \multirow{3}{*}{ WPV } & \multicolumn{8}{|c|}{ Mean FMD serotype-A antibody titers in sheep vaccinated with } \\
\hline & \multicolumn{2}{|c|}{ Formula-1 } & \multicolumn{2}{|c|}{ Formula-2 } & \multicolumn{2}{|c|}{ Formula-3 } & \multicolumn{2}{|c|}{ Formula-4 } \\
\hline & SNT & ELISA & SNT & ELISA & SNT & ELISA & SNT & ELISA \\
\hline \multirow[t]{2}{*}{0} & 0.27 & 0.39 & 0.27 & 0.55 & 0.27 & 0.55 & 0.3 & 0.6 \\
\hline & $\pm 0.073^{\mathrm{a}}$ & $\pm 0.070^{\mathrm{a}}$ & $\pm 0.088^{\mathrm{a}}$ & $\pm 0.099^{\mathrm{a}}$ & $\pm 0.010^{\mathrm{a}}$ & $\pm 0.036^{\mathrm{a}}$ & $\pm 0.047^{\mathrm{a}}$ & $\pm 0.059^{\mathrm{a}}$ \\
\hline \multirow[t]{2}{*}{1} & 1.02 & 1.24 & 1 & 1.26 & 1.02 & 1.29 & 1.48 & 1.61 \\
\hline & $\pm 0.110^{\mathrm{a}}$ & $\pm 0.111^{\mathrm{a}}$ & $\pm 0.010^{\mathrm{a}}$ & $\pm 0.015^{\mathrm{a}}$ & $\pm 0.060^{\mathrm{a}, \mathrm{b}}$ & $\pm 0.076^{\mathrm{b}}$ & $\pm 0.075^{\mathrm{b}}$ & $\pm 0.089^{\mathrm{b}}$ \\
\hline \multirow[t]{2}{*}{2} & 1.33 & 1.61 & 1.52 & 1.8 & 1.59 & 1.84 & 1.71 & 1.82 \\
\hline & $\pm 0.080^{\mathrm{a}}$ & $\pm 0.070^{\mathrm{a}}$ & $\pm 0.080^{\mathrm{a}}$ & $\pm 0.082^{\mathrm{a}}$ & $\pm 0.100^{\mathrm{a}}$ & $\pm 0.022^{\mathrm{a}}$ & $\pm 0.035^{\mathrm{a}}$ & $\pm 0.039^{\mathrm{a}}$ \\
\hline \multirow[t]{2}{*}{3} & 1.52 & 1.82 & 1.72 & 2 & 1.77 & 2.04 & 1.87 & 2.3 \\
\hline & $\pm 0.060^{\mathrm{a}}$ & $\pm 0.050^{\mathrm{b}}$ & $\pm 0.092^{\mathrm{a}}$ & $\pm 0.113^{\mathrm{a}}$ & $\pm 0.072^{\mathrm{a}}$ & $\pm 0.047^{\mathrm{a}}$ & $\pm 0.051^{\mathrm{a}}$ & $\pm 0.069^{\mathrm{a}}$ \\
\hline \multirow[t]{2}{*}{4} & 1.85 & 2.21 & 1.9 & 2.28 & 1.92 & 2.32 & 2.3 & 2.53 \\
\hline & $\pm 0.047^{\mathrm{b}}$ & $\pm 0.041^{\mathrm{b}}$ & $\pm 0.075^{\mathrm{a}}$ & $\pm 0.083^{\mathrm{a}}$ & $\pm 0.065^{\mathrm{a}}$ & $\pm 0.052^{\mathrm{a}}$ & $\pm 0.060^{\mathrm{a}}$ & $\pm 0.069^{\mathrm{a}}$ \\
\hline \multirow[t]{2}{*}{6} & 2.14 & 2.19 & 2.18 & 2.5 & 2.2 & 2.52 & 2.68 & 2.9 \\
\hline & $\pm 0.090^{\mathrm{b}}$ & $\pm 0.082^{\mathrm{b}}$ & $\pm 0.005^{\mathrm{a}}$ & $\pm 0.009^{\mathrm{a}}$ & $\pm 0.068^{\mathrm{a}}$ & $\pm 0.036^{\mathrm{a}}$ & $\pm 0.043^{\mathrm{a}}$ & $\pm 0.048^{\mathrm{a}}$ \\
\hline \multirow[t]{2}{*}{8} & 2.43 & 2.61 & 2.61 & 2.92 & 2.65 & 2.96 & 3.24 & 3.45 \\
\hline & $\pm 0.030^{\mathrm{a}}$ & $\pm 0.022^{\mathrm{b}}$ & $\pm 0.075^{\mathrm{a}}$ & $\pm 0.084^{\mathrm{a}}$ & $\pm 0.052^{\mathrm{b}}$ & $\pm 0.101^{\mathrm{a}}$ & $\pm 0.108^{\mathrm{a}}$ & $\pm 0.111^{\mathrm{a}}$ \\
\hline \multirow[t]{2}{*}{10} & 2.54 & 2.83 & 2.91 & 3.17 & 3 & 3.27 & 3.18 & 3.38 \\
\hline & $\pm 0.006^{\mathrm{a}, \mathrm{b}}$ & $\pm 0.050^{\mathrm{a}}$ & $\pm 0.006^{\mathrm{a}}$ & $\pm 0.008^{\mathrm{a}}$ & $\pm 0.054^{\mathrm{b}}$ & $\pm 0.060^{\mathrm{a}, \mathrm{b}}$ & $\pm 0.074^{\mathrm{a}}$ & $\pm 0.084^{\mathrm{a}}$ \\
\hline \multirow[t]{2}{*}{12} & 2.65 & 2.96 & 2.81 & 3.04 & 2.91 & 3.18 & 3.1 & 3.3 \\
\hline & $\pm 0.040^{\mathrm{b}}$ & $\pm 0.045^{\mathrm{b}}$ & $\pm 0.013^{\mathrm{a}}$ & $\pm 0.019^{\mathrm{a}}$ & $\pm 0.037^{\mathrm{c}}$ & $\pm 0.092^{\mathrm{a}, \mathrm{b}}$ & $\pm 0.098^{\mathrm{b}}$ & $\pm 0.099^{\mathrm{b}}$ \\
\hline \multirow[t]{2}{*}{14} & 2.76 & 3.01 & 2.81 & 3.04 & 2.89 & 3.12 & 2.9 & 3.15 \\
\hline & $\pm 0.006^{\mathrm{a}}$ & $\pm 0.110^{\mathrm{a}}$ & $\pm 0.105^{\mathrm{a}}$ & $\pm 0.109^{\mathrm{a}}$ & $\pm 0.042^{\mathrm{a}}$ & $\pm 0.032^{\mathrm{b}}$ & $\pm 0.038^{\mathrm{b}}$ & $\pm 0.049^{\mathrm{b}}$ \\
\hline \multirow[t]{2}{*}{16} & 2.45 & 2.76 & 2.55 & 2.86 & 2.62 & 2.94 & 2.71 & 3.08 \\
\hline & $\pm 0.130^{\mathrm{a}}$ & $\pm 0.006^{\mathrm{a}}$ & $\pm 0.112^{\mathrm{a}}$ & $\pm 0.120^{\mathrm{a}}$ & $\pm 0.009^{\mathrm{a}, \mathrm{b}}$ & $\pm 0.071^{\mathrm{b}}$ & $\pm 0.087^{\mathrm{b}}$ & $\pm 0.092^{\mathrm{b}}$ \\
\hline \multirow[t]{2}{*}{20} & 2.21 & 2.54 & 2.3 & 2.63 & 2.38 & 2.65 & 2.42 & 2.7 \\
\hline & $\pm 0.050^{\mathrm{b}}$ & $\pm 0.050^{\mathrm{a}}$ & $\pm 0.008^{\mathrm{a}}$ & $\pm 0.010^{\mathrm{a}}$ & $\pm 0.066^{\mathrm{a}}$ & $\pm 0.069^{\mathrm{a}}$ & $\pm 0.074^{\mathrm{a}}$ & $\pm 0.084^{\mathrm{a}}$ \\
\hline \multirow[t]{2}{*}{24} & 1.91 & 2.3 & 1.99 & 2.4 & 2.12 & 2.43 & 2.21 & 2.51 \\
\hline & $\pm 0.040^{\mathrm{a}}$ & $\pm 0.055^{\mathrm{a}, \mathrm{b}}$ & $\pm 0.090^{\mathrm{a}}$ & $\pm 0.097^{\mathrm{a}}$ & $\pm 0.109^{\mathrm{a}, \mathrm{b}}$ & $\pm 0.071^{\mathrm{a}, \mathrm{b}}$ & $\pm 0.076^{\mathrm{a}}$ & $\pm 0.082^{\mathrm{a}}$ \\
\hline \multirow[t]{2}{*}{28} & 1.75 & 2.03 & 1.82 & 2.13 & 1.95 & 2.43 & 2.09 & 2.47 \\
\hline & $\pm 0.050^{\mathrm{b}}$ & $\pm 0.050^{\mathrm{a}}$ & $\pm 0.082^{\mathrm{a}}$ & $\pm 0.087^{\mathrm{a}}$ & $\pm 0.103^{\mathrm{b}}$ & $\pm 0.072^{\mathrm{a}, \mathrm{b}}$ & $\pm 0.076^{\mathrm{a}}$ & $\pm 0.091^{\mathrm{a}}$ \\
\hline \multirow[t]{2}{*}{32} & 1.65 & 1.89 & 1.66 & 1.99 & 1.8 & 2.19 & 1.83 & 2.21 \\
\hline & $\pm 0.060^{\mathrm{c}}$ & $\pm 0.101^{\mathrm{a}}$ & $\pm 0.081^{\mathrm{a}}$ & $\pm 0.086^{\mathrm{a}}$ & $\pm 0.052^{\mathrm{c}}$ & $\pm 0.111^{\mathrm{b}}$ & $\pm 0.124^{\mathrm{b}}$ & $\pm 0.132^{\mathrm{a}, \mathrm{b}}$ \\
\hline \multirow[t]{2}{*}{36} & 1.05 & 1.24 & 1.15 & 1.29 & 1.73 & 1.92 & 1.75 & 1.95 \\
\hline & $\pm 0.060^{\mathrm{a}}$ & $\pm 0.060^{\mathrm{c}}$ & $\pm 0.089^{\mathrm{a}}$ & $\pm 0.093^{\mathrm{a}}$ & $\pm 0.083^{\mathrm{c}}$ & $\pm 0.052^{\mathrm{b}}$ & $\pm 0.057^{\mathrm{b}}$ & $\pm 0.069^{\mathrm{b}}$ \\
\hline \multirow[t]{2}{*}{40} & 0.62 & 0.96 & 0.71 & 0.99 & 1.4 & 1.65 & 1.47 & 1.68 \\
\hline & $\pm 0.070^{\mathrm{b}}$ & $\pm 0.007^{\mathrm{b}}$ & $\pm 0.066^{\mathrm{a}}$ & $\pm 0.071^{\mathrm{a}}$ & $\pm 0.101^{\mathrm{a}, \mathrm{b}}$ & $\pm 0.063^{\mathrm{a}, \mathrm{b}}$ & $\pm 0.075^{\mathrm{a}}$ & $\pm 0.083^{\mathrm{a}}$ \\
\hline
\end{tabular}

$\mathrm{SNT}=$ Serum neutralization test, ELISA=Enzyme linked immune sorbent assay, WPV=Week post vaccination, $\mathrm{SE}=\mathrm{Standard}$ error, FMDV=Foot and mouth disease virus, different letters indicate significant difference between different treatments at $\mathrm{p}<0.05$ according to Duncan's multiple range test 


\section{El-Sayed, E. I. et al.....}

Table 8. FMD serotype-SAT2/2012 serum neutralizing antibody titer and ELISA (expressed as $\log _{10}$ ) in different vaccinated sheep groups

\begin{tabular}{|c|c|c|c|c|c|c|c|c|}
\hline \multirow{3}{*}{ WPV } & \multicolumn{8}{|c|}{ Mean FMD serotype-SAT2/2012 antibody titers in sheep vaccinated with } \\
\hline & \multicolumn{2}{|c|}{ Formula-1 } & \multicolumn{2}{|c|}{ Formula-2 } & \multicolumn{2}{|c|}{ Formula-3 } & \multicolumn{2}{|c|}{ Formula-4 } \\
\hline & SNT & ELISA & SNT & ELISA & SNT & ELISA & SNT & ELISA \\
\hline \multirow[t]{2}{*}{0} & 0.15 & 0.4 & 0.41 & 0.66 & 0.51 & 0.76 & 0.3 & 0.6 \\
\hline & $\pm 0.006^{\mathrm{a}}$ & $\pm 0.077^{\mathrm{a}}$ & $\pm 0.052^{\mathrm{a}}$ & $\pm 0.064^{\mathrm{a}}$ & $\pm 0.015^{\mathrm{a}}$ & $\pm 0.032^{\mathrm{a}}$ & $\pm 0.042^{\mathrm{a}}$ & $\pm 0.049^{\mathrm{a}}$ \\
\hline \multirow[t]{2}{*}{1} & 0.23 & 1.52 & 1.22 & 1.48 & 1.32 & 1.57 & 1.48 & 1.61 \\
\hline & $\pm 0.080^{\mathrm{b}}$ & $\pm 0.1^{\mathrm{b}}$ & $\pm 0.081^{\mathrm{a}}$ & $\pm 0.092^{\mathrm{a}}$ & $\pm 0.060^{\mathrm{a}, \mathrm{b}}$ & $\pm 0.019^{\mathrm{a}}$ & $\pm 0.065^{\mathrm{b}}$ & $\pm 0.062^{\mathrm{a}}$ \\
\hline \multirow[t]{2}{*}{2} & 1.35 & 1.67 & 1.67 & 1.86 & 1.71 & 1.96 & 1.87 & 2.2 \\
\hline & $\pm 0.006^{\mathrm{b}}$ & $\pm 0.072^{\mathrm{b}}$ & $\pm 0.101^{\mathrm{b}}$ & $\pm 0.105^{\mathrm{b}}$ & $\pm 0.126^{\mathrm{a}}$ & $\pm 0.096^{\mathrm{a}}$ & $\pm 0.043^{\mathrm{a}}$ & $\pm 0.046^{\mathrm{a}}$ \\
\hline \multirow[t]{2}{*}{3} & 1.55 & 1.91 & 1.87 & 2.12 & 1.92 & 2.17 & 2.32 & 2.55 \\
\hline & $\pm 0.052^{\mathrm{b}}$ & $\pm 0.063^{\mathrm{b}}$ & $\pm 0.062^{\mathrm{a}}$ & $\pm 0.06^{\mathrm{a}}$ & $\pm 0.060^{\mathrm{a}}$ & $\pm 0.060^{\mathrm{a}}$ & $\pm 0.021^{\mathrm{a}}$ & $\pm 0.023^{\mathrm{a}}$ \\
\hline \multirow[t]{2}{*}{4} & 1.84 & 2.16 & 2.1 & 2.35 & 2.19 & 2.44 & 2.71 & 2.93 \\
\hline & $\pm 0.005^{\mathrm{b}}$ & $\pm 0.003^{\mathrm{b}}$ & $\pm 0.104^{\mathrm{a}}$ & $\pm 0.109^{\mathrm{a}}$ & $\pm 0.060^{\mathrm{a}}$ & $\pm 0.080^{\mathrm{a}}$ & $\pm 0.050^{\mathrm{a}}$ & $\pm 0.054^{\mathrm{a}}$ \\
\hline \multirow[t]{2}{*}{6} & 2.14 & 2.36 & 2.31 & 2.52 & 2.37 & 2.62 & 2.92 & 3.25 \\
\hline & $\pm 0.053^{\mathrm{a}, \mathrm{b}}$ & $\pm 0.062^{\mathrm{a}, \mathrm{b}}$ & $\pm 0.112^{\mathrm{a}, \mathrm{b}}$ & $\pm 0.119^{\mathrm{a}, \mathrm{b}}$ & $\pm 0.094^{\mathrm{c}}$ & $\pm 0.045^{\mathrm{b}}$ & $\pm 0.101^{\mathrm{a}, \mathrm{b}}$ & $\pm 0.104^{\mathrm{a}, \mathrm{b}}$ \\
\hline \multirow[t]{2}{*}{8} & 2.42 & 2.69 & 2.71 & 2.95 & 2.76 & 3.01 & 3.18 & 3.38 \\
\hline & $\pm 0.002^{\mathrm{a}}$ & $\pm 0.070^{\mathrm{a}}$ & $\pm 0.139^{\mathrm{a}}$ & $\pm 0.144^{\mathrm{a}}$ & $\pm 0.055^{\mathrm{b}}$ & $\pm 0.042^{\mathrm{b}}$ & $\pm 0.063^{\mathrm{a}}$ & $\pm 0.069^{\mathrm{a}}$ \\
\hline \multirow[t]{2}{*}{10} & 2.42 & 2.69 & 3.01 & 3.26 & 3.09 & 3.34 & 3.33 & 3.55 \\
\hline & $\pm 0.076^{\mathrm{a}, \mathrm{b}}$ & $\pm 0.091^{\mathrm{a}, \mathrm{b}}$ & $\pm 0.072^{\mathrm{a}}$ & $\pm 0.072^{\mathrm{a}}$ & $\pm 0.043^{\mathrm{b}}$ & $\pm 0.043^{\mathrm{b}}$ & $\pm 0.092^{\mathrm{a}, \mathrm{b}}$ & $\pm 0.096^{\mathrm{a}, \mathrm{b}}$ \\
\hline \multirow[t]{2}{*}{12} & 2.55 & 2.83 & 2.87 & 3.12 & 2.97 & 3.22 & 3.15 & 3.36 \\
\hline & $\pm 0.003^{\mathrm{a}}$ & $\pm 0.030^{\mathrm{a}}$ & $\pm 0.053^{\mathrm{a}}$ & $\pm 0.055^{\mathrm{a}}$ & $\pm 0.035^{\mathrm{c}}$ & $\pm 0.039^{\mathrm{b}}$ & $\pm 0.074^{\mathrm{a}}$ & $\pm 0.077^{\mathrm{a}}$ \\
\hline \multirow[t]{2}{*}{14} & 2.71 & 2.93 & 2.76 & 3 & 2.82 & 3.07 & 3 & 3.24 \\
\hline & $\pm 0.003^{\mathrm{c}}$ & $\pm 0.025^{\mathrm{c}}$ & $\pm 0.09^{\mathrm{b}}$ & $\pm 0.086^{\mathrm{a}}$ & $\pm 0.055^{\mathrm{a}}$ & $\pm 0.054^{\mathrm{a}, \mathrm{b}}$ & $\pm 0.081^{\mathrm{a}}$ & $\pm 0.085^{\mathrm{a}}$ \\
\hline \multirow[t]{2}{*}{16} & 2.51 & 2.73 & 2.61 & 2.86 & 2.61 & 2.86 & 2.71 & 3.08 \\
\hline & $\pm 0.005^{\mathrm{b}}$ & $\pm 0.022^{\mathrm{b}}$ & $\pm 0.071^{\mathrm{b}}$ & $\pm 0.048^{\mathrm{a}}$ & $\pm 0.06^{\mathrm{a}, \mathrm{b}}$ & $\pm 0.032^{\mathrm{a}, \mathrm{b}}$ & $\pm 0.077^{\mathrm{a}}$ & $\pm 0.077^{\mathrm{a}}$ \\
\hline \multirow[t]{2}{*}{20} & 2.33 & 2.54 & 2.47 & 2.62 & 2.47 & 2.62 & 2.49 & 2.7 \\
\hline & $\pm 0.004^{\mathrm{b}}$ & $\pm 0.026^{\mathrm{b}}$ & $\pm 0.072^{\mathrm{a}}$ & $\pm 0.049^{\mathrm{a}}$ & $\pm 0.084^{\mathrm{a}}$ & $\pm 0.092^{\mathrm{b}}$ & $\pm 0.101^{\mathrm{a}}$ & $\pm 0.109^{\mathrm{a}}$ \\
\hline \multirow[t]{2}{*}{24} & 2.14 & 2.43 & 2.14 & 2.43 & 2.26 & 2.51 & 2.31 & 2.61 \\
\hline & $\pm 0.006^{\mathrm{b}}$ & $\pm 0.062^{\mathrm{b}, \mathrm{c}}$ & $\pm 0.10^{\mathrm{a}}$ & $\pm 0.15^{\mathrm{a}}$ & $\pm 0.101^{\mathrm{a}, \mathrm{b}}$ & $\pm 0.114^{\mathrm{a}}$ & $\pm 0.022^{\mathrm{a}}$ & $\pm 0.029^{\mathrm{a}}$ \\
\hline \multirow[t]{2}{*}{28} & 1.81 & 2.16 & 1.81 & 2.16 & 1.95 & 2.23 & 2.02 & 2.27 \\
\hline & $\pm 0.007^{\mathrm{b}}$ & $\pm 0.042^{\mathrm{b}}$ & $\pm 0.070^{\mathrm{a}}$ & $\pm 0.074^{\mathrm{a}}$ & $\pm 0.113^{\mathrm{b}}$ & $\pm 0.102^{\mathrm{b}, \mathrm{c}}$ & $\pm 0.06^{\mathrm{a}}$ & $\pm 0.07^{\mathrm{a}}$ \\
\hline \multirow[t]{2}{*}{32} & 1.65 & 1.92 & 1.65 & 1.92 & 1.86 & 2.04 & 1.89 & 2.1 \\
\hline & $\pm 0.009^{\mathrm{b}}$ & $\pm 0.021^{\mathrm{b}}$ & $\pm 0.023^{\mathrm{a}}$ & $\pm 0.029^{\mathrm{a}}$ & $\pm 0.052^{\mathrm{c}}$ & $\pm 0.09^{\mathrm{a}}$ & $\pm 0.021^{\mathrm{a}}$ & $\pm 0.024^{\mathrm{a}, \mathrm{b}}$ \\
\hline \multirow[t]{2}{*}{36} & 1.22 & 1.48 & 1.22 & 1.48 & 1.68 & 1.97 & 1.73 & 1.99 \\
\hline & $\pm 0.101^{\mathrm{b}}$ & $\pm 0.093^{\mathrm{b}}$ & $\pm 0.114^{\mathrm{a}}$ & $\pm 0.123^{\mathrm{a}}$ & $\pm 0.062^{\mathrm{c}}$ & $\pm 0.069^{\mathrm{a}}$ & $\pm 0.121^{\mathrm{a}, \mathrm{b}}$ & $\pm 0.130^{\mathrm{a}, \mathrm{b}}$ \\
\hline \multirow[t]{2}{*}{40} & 0.75 & 1.04 & 0.75 & 1.04 & 1.47 & 1.72 & 1.47 & 1.68 \\
\hline & $\pm 0.122^{\mathrm{a}}$ & $\pm 0.134^{\mathrm{a}}$ & $\pm 0.140^{\mathrm{a}}$ & $\pm 0.145^{\mathrm{a}}$ & $\pm 0.101^{\mathrm{a}, \mathrm{b}}$ & $\pm 0.06^{\mathrm{a}}$ & $\pm 0.070^{\mathrm{a}, \mathrm{b}}$ & $\pm 0.075^{\mathrm{a}}$ \\
\hline
\end{tabular}

SNT=Serum neutralization test, ELISA=Enzyme linked immune sorbent assay, WPV=Week post vaccination, SE=Standard error, FMDV=Foot and mouth disease virus, different letters indicate significant difference between different treatments at $\mathrm{p}<0.05$ according to Duncan's multiple range test 
Table 9. FMD serotype-SAT2/2018 serum neutralizing antibody titer and ELISA (expressed as log10) in different vaccinated sheep groups

\begin{tabular}{|c|c|c|c|c|c|c|c|c|}
\hline \multirow{3}{*}{ WPV } & \multicolumn{8}{|c|}{ Mean FMD serotype-SAT2/2018 antibody titers in sheep vaccinated with } \\
\hline & \multicolumn{2}{|c|}{ Formula-1 } & \multicolumn{2}{|c|}{ Formula-2 } & \multicolumn{2}{|c|}{ Formula-3 } & \multicolumn{2}{|c|}{ Formula-4 } \\
\hline & SNT & ELISA & SNT & ELISA & SNT & ELISA & SNT & ELISA \\
\hline \multirow[t]{2}{*}{0} & 0.31 & 0.44 & 0.42 & 0.76 & 0.62 & 0.86 & 0.51 & 0.76 \\
\hline & $\pm 0.03^{\mathrm{a}}$ & $\pm 0.06^{\mathrm{a}}$ & $\pm 0.09^{\mathrm{a}}$ & $\pm 0.144^{\mathrm{a}}$ & $\pm 0.084^{\mathrm{a}}$ & $\pm 0.073^{\mathrm{a}}$ & $\pm 0.009^{\mathrm{b}}$ & $\pm 0.040^{\mathrm{b}}$ \\
\hline \multirow[t]{2}{*}{1} & 1.24 & 1.46 & 1.39 & 1.61 & 1.41 & 1.67 & 1.46 & 1.77 \\
\hline & $\pm 0.076^{\mathrm{a}, \mathrm{b}}$ & $\pm 0.094^{\mathrm{a}}$ & $\pm 0.092^{\mathrm{b}}$ & $\pm 0.068^{\mathrm{b}}$ & $\pm 0.118^{\mathrm{a}}$ & $\pm 0.139^{\mathrm{a}}$ & $\pm 0.082^{\mathrm{c}}$ & $\pm 0.008^{\mathrm{b}}$ \\
\hline \multirow[t]{2}{*}{2} & 1.24 & 1.46 & 1.62 & 1.98 & 1.68 & 2.01 & 1.71 & 2.2 \\
\hline & $\pm 0.137^{\mathrm{a}}$ & $\pm 0.139^{\mathrm{a}}$ & $\pm 0.087^{\mathrm{b}}$ & $\pm 0.139^{\mathrm{b}}$ & $\pm 0.088^{\mathrm{a}}$ & $\pm 0.06^{\mathrm{b}}$ & $\pm 0.010^{\mathrm{a}}$ & $\pm 0.019^{\mathrm{a}}$ \\
\hline \multirow[t]{2}{*}{3} & 1.55 & 1.92 & 1.87 & 2.05 & 1.91 & 2.12 & 2.01 & 2.25 \\
\hline & $\pm 0.056^{\mathrm{a}, \mathrm{b}}$ & $\pm 0.087^{\mathrm{a}}$ & $\pm 0.056^{\mathrm{b}, \mathrm{c}}$ & $\pm 0.047^{\mathrm{a}, \mathrm{b}}$ & $\pm 0.045^{\mathrm{a}}$ & $\pm 0.112^{\mathrm{a}, \mathrm{b}}$ & $\pm 0.050^{\mathrm{a}}$ & $\pm 0.060^{\mathrm{a}}$ \\
\hline \multirow[t]{2}{*}{4} & 1.95 & 2.13 & 2.01 & 2.22 & 2.08 & 2.32 & 2.19 & 2.44 \\
\hline & $\pm 0.102^{\mathrm{a}}$ & $\pm 0.09^{c}$ & $\pm 0.102^{\mathrm{b}}$ & $\pm 0.139^{\mathrm{a}}$ & $\pm 0.102^{\mathrm{a}}$ & $\pm 0.102^{\mathrm{a}}$ & $\pm 0.069^{\mathrm{a}}$ & $\pm 0.109^{\mathrm{a}}$ \\
\hline \multirow[t]{2}{*}{6} & 2.01 & 2.21 & 2.21 & 2.43 & 2.31 & 2.53 & 2.76 & 3.01 \\
\hline & $\pm 0.087^{\mathrm{b}}$ & $\pm 0.114^{\mathrm{a}}$ & $\pm 0.083^{\mathrm{b}}$ & $\pm 0.083^{\mathrm{b}}$ & $\pm 0.047^{\mathrm{a}, \mathrm{b}}$ & $\pm 0.034^{\mathrm{b}}$ & $\pm 0.054^{\mathrm{b}}$ & $\pm 0.034^{\mathrm{a}, \mathrm{b}}$ \\
\hline \multirow[t]{2}{*}{8} & 2.15 & 2.25 & 2.61 & 2.84 & 2.7 & 2.94 & 3.36 & 3.58 \\
\hline & $\pm 0.050^{\mathrm{c}}$ & $\pm 0.122^{\mathrm{a}}$ & $\pm 0.037^{\mathrm{a}}$ & $\pm 0.157^{\mathrm{a}}$ & $\pm 0.066^{\mathrm{b}}$ & $\pm 0.075^{\mathrm{b}}$ & $\pm 0.097^{\mathrm{a}}$ & $\pm 0.139^{\mathrm{a}}$ \\
\hline \multirow[t]{2}{*}{10} & 2.23 & 2.31 & 2.94 & 3.17 & 3.01 & 3.27 & 3.19 & 3.38 \\
\hline & $\pm 0.102^{\mathrm{a}}$ & $\pm 0.06^{\mathrm{a}, \mathrm{c}}$ & $\pm 0.04^{\mathrm{b}}$ & $\pm 0.050^{\mathrm{b}}$ & $\pm 0.102^{\mathrm{b}}$ & $\pm 0.114^{\mathrm{a}}$ & $\pm 0.132^{\mathrm{a}}$ & $\pm 0.056^{\mathrm{b}, \mathrm{c}}$ \\
\hline \multirow[t]{2}{*}{12} & 2.31 & 2.51 & 2.76 & 3.04 & 2.83 & 3.12 & 3.02 & 3.25 \\
\hline & $\pm 0.141^{\mathrm{a}, \mathrm{b}}$ & $\pm 0.056^{\mathrm{b}, \mathrm{c}}$ & $\pm 0.083^{\mathrm{b}}$ & $\pm 0.111^{\mathrm{b}}$ & $\pm 0.073^{\mathrm{b}}$ & $\pm 0.139^{\mathrm{a}}$ & $\pm 0.101^{\mathrm{a}, \mathrm{b}}$ & $\pm 0.112^{\mathrm{b}}$ \\
\hline \multirow[t]{2}{*}{14} & 2.54 & 2.8 & 2.81 & 3.07 & 2.81 & 3.07 & 2.92 & 3.15 \\
\hline & $\pm 0.056^{\mathrm{a}}$ & $\pm 0.144^{\mathrm{a}}$ & $\pm 0.047^{\mathrm{a}, \mathrm{b}}$ & $\pm 0.071^{\mathrm{a}}$ & $\pm 0.090^{\mathrm{a}}$ & $\pm 0.05^{\mathrm{b}}$ & $\pm 0.066^{\mathrm{a}}$ & $\pm 0.102^{\mathrm{b}}$ \\
\hline \multirow[t]{2}{*}{16} & 2.42 & 2.61 & 2.61 & 2.81 & 2.61 & 2.81 & 2.72 & 2.89 \\
\hline & $\pm 0.064^{\mathrm{a}}$ & $\pm 0.053^{\mathrm{a}}$ & $\pm 0.050^{\mathrm{a}, \mathrm{b}}$ & $\pm 0.084^{\mathrm{a}}$ & $\pm 0.120^{\mathrm{a}, \mathrm{c}}$ & $\pm 0.091^{\mathrm{a}, \mathrm{b}}$ & $\pm 0.015^{\mathrm{a}}$ & $\pm 0.03^{\mathrm{b}}$ \\
\hline \multirow[t]{2}{*}{20} & 2.1 & 2.2 & 2.11 & 2.21 & 2.31 & 2.51 & 2.47 & 2.68 \\
\hline & $\pm 0.036^{\mathrm{b}}$ & $\pm 0.073^{\mathrm{a}}$ & $\pm 0.112^{\mathrm{a}}$ & $\pm 0.042^{\mathrm{a}}$ & $\pm 0.050^{\mathrm{c}}$ & $\pm 0.076^{\mathrm{a}}$ & $\pm 0.050^{\mathrm{a}, \mathrm{b}}$ & $\pm 0.09^{\mathrm{a}}$ \\
\hline \multirow[t]{2}{*}{24} & 2.1 & 2.2 & 2.16 & 2.29 & 2.26 & 2.49 & 2.36 & 2.59 \\
\hline & $\pm 0.076^{\mathrm{a}, \mathrm{b}}$ & $\pm 0.102^{\mathrm{b}}$ & $\pm 0.056^{\mathrm{a}}$ & $\pm 0.060^{\mathrm{c}}$ & $\pm 0.077^{\mathrm{b}}$ & $\pm 0.114^{\mathrm{a}}$ & $\pm 0.084^{\mathrm{a}}$ & $\pm 0.084^{\mathrm{a}}$ \\
\hline \multirow[t]{2}{*}{28} & 1.65 & 1.94 & 1.7 & 2.26 & 2.01 & 2.26 & 2.15 & 2.33 \\
\hline & $\pm 0.037^{\mathrm{a}}$ & $\pm 0.114^{\mathrm{a}}$ & $\pm 0.139^{\mathrm{a}}$ & $\pm 0.008^{\mathrm{a}}$ & $\pm 0.103^{\mathrm{a}}$ & $\pm 0.03^{\mathrm{b}}$ & $\pm 0.009^{\mathrm{a}, \mathrm{b}}$ & $\pm 0.114^{\mathrm{a}}$ \\
\hline \multirow[t]{2}{*}{32} & 1.51 & 1.81 & 1.76 & 1.87 & 1.86 & 2.09 & 1.86 & 2.18 \\
\hline & $\pm 0.102^{\mathrm{a}}$ & $\pm 0.110^{\mathrm{a}, \mathrm{b}}$ & $\pm 0.141^{\mathrm{a}, \mathrm{b}}$ & $\pm 0.010^{\mathrm{a}}$ & $\pm 0.110^{\mathrm{a}}$ & $\pm 0.1^{\mathrm{b}}$ & $\pm 0.120^{\mathrm{c}}$ & $\pm 0.04^{\mathrm{b}}$ \\
\hline \multirow[t]{2}{*}{36} & 1.24 & 1.59 & 1.48 & 1.68 & 1.71 & 2.04 & 1.86 & 2.18 \\
\hline & $\pm 0.137^{\mathrm{a}}$ & $\pm 0.09^{\mathrm{a}}$ & $\pm 0.056^{\mathrm{b}, \mathrm{c}}$ & $\pm 0.047^{\mathrm{b}}$ & $\pm 0.010^{\mathrm{a}, \mathrm{b}}$ & $\pm 0.062^{\mathrm{b}, \mathrm{c}}$ & $\pm 0.048^{\mathrm{b}}$ & $\pm 0.141^{\mathrm{c}}$ \\
\hline \multirow[t]{2}{*}{40} & 0.61 & 0.93 & 1.42 & 1.61 & 1.42 & 1.61 & 1.47 & 1.72 \\
\hline & $\pm 0.03^{\mathrm{b}}$ & $\pm 0.139^{\mathrm{b}}$ & $\pm 0.101^{\mathrm{c}}$ & $\pm 0.022^{\mathrm{b}}$ & $\pm 0.037^{\mathrm{c}}$ & $\pm 0.076^{\mathrm{a}, \mathrm{b}}$ & $\pm 0.123^{\mathrm{b}}$ & $\pm 0.09^{\mathrm{b}}$ \\
\hline
\end{tabular}

SNT=Serum neutralization test, ELISA=Enzyme linked immune sorbent assay, WPV=Week post vaccination, SE=Standard error, FMDV=Foot and mouth disease virus, different letters indicate significant difference between different treatments at $\mathrm{p}<0.05$ according to Duncan's multiple range test 


\section{El-Sayed, E. I. et al.....}

\section{DISCISSION}

Foot and Mouth Disease (FMD) is an acute disease caused by Foot and Mouth Disease Virus (FMDV) which causes important economic losses (Orsel et al., 2007). The control of FMD in animals is considered to be important and effective in limiting the spread of infection through effective vaccination using safe and potent FMD vaccine with local circulating FMDV serotypes to give high and early onset of protection with long duration especially in endemic areas as Egypt. FMD vaccines can be defined as a fixed formulation of specific amount of chemically inactivated virus strains mixed with suitable adjuvant. Selecting the suitable vaccine formulation is dependent on several factors as the onset of protection, the duration of protection against FMD and the target species being vaccinated.

The effective formulation of inactivated FMD vaccines requires adjuvant as aluminum hydroxide gel and mineral oils-based formulations which have been widely employed in experimental studies to obtain a vaccine that stimulates a rapid and long-lasting protective immune response and it must be safe for animal use. From this concern, continuous researches must be applied to reach a highly potent with long lived post vaccinal immunogenicity with safety issue .So, this research is interested in comparing between different vaccine formulations differ in the adjuvant added as four vaccine formulations were prepared using Montanide ISA 206 (Formula-1) ,Montanide ISA 206 mixed with Aluminium hydroxide gel (Formula-2), Montanide ISA 201 (Formula-3) and Montanide ISA 201 mixed with aluminium hydroxide gel(Formula-4). Firstly safety test of the prepared vaccines was done in mice and the results showed that the four prepared vaccines were safe for animal use during the whole experiment time and agreed with the requirements of vaccine preparation of OIE (2017), Table (1).

Regarding the cellular immune response of sheep to different FMD vaccine formulae, evaluation of the cellular immunity included were done through estimation of the lymphocyte blastogenesis, phagocytic percentage, phagocytic index in addition to IL-6 levels. The efficient induction of early protection against contact infections by FMDV relies on the rapid assimilation of appropriate innate immune defense, probably leading to the enhanced induction of specific immune responses (Barnett $\boldsymbol{e t}$ al., 2002). Table (2) showed that the cellular immune response of sheep to the inactivated FMD ISA 206 oil vaccine (Formula-1) revealed increasing mean delta optical density of lymphocyte blastogenesis assay at day 1, 3, 7, 14, 21 and $28 \mathrm{DPV}$ from 0.11 at the day 1 to reach its maximum value $(0.61)$ at the $21^{\text {st }} \mathrm{DPV}$ then declined at the $28^{\text {st }}$ DPV (0.50), but in sheep vaccinated with inactivated FMD 206 oil with aluminum hydroxide gel vaccine (Formula-2), showed an increase in the mean value from $(0.22)$ at the day 1 to reach its maximum value $(0.99)$ at the $7^{\text {th }}$ DPV then declined at the $14^{\text {th }}$ DPV (0.74) while the inactivated FMD Montanide 201 oil (Formula-3) revealed increasing from 0.32 at the day 1 to reach its maximum value (1.01) at the $7^{\text {th }}$ DPV then declined at the $14^{\text {th }}$ DPV $(0.80)$, finally, sheep vaccinated with inactivated FMD ISA 201 oil with aluminum hydroxide gel vaccine (Formula-4) showed mean delta optical density of lymphocyte blastogenesis assay increasing from 0.33 at the day 1 to reach its maximum value (1.21) at the $7^{\text {th }} \mathrm{DPV}$ then declined at the $14^{\text {th }} \mathrm{DPV}(0.99)$, but the control sheep remain mean delta optical density of lymphocyte blastogenesis assay around 0.10 to 0.13 allover the time of estimation.

Tables $(3,4)$ showed that the cellular immune response of sheep to the inactivated FMD ISA 206 oil vaccine (Formula-1) revealed increasing phagocytic \% and Phagocytic index at day 1, 3, 7, 14, 21 and 28 DPV from (20.1 and 0.11 respectively) at the day 1 to reach its maximum value $\left(66.4,0.69\right.$ respectively) at the $21^{\text {st }}$ DPV then declined at the $28^{\text {st }}$ DPV (54.2 and 0.45 respectively) but in sheep vaccinated with inactivated FMD 206 oil with aluminum hydroxide gel vaccine (Formula-2), showed an increase in the mean value of phagocytic \% and Phagocytic index from (23 and 0.10 respectively) at the day 1 to reach its maximum value (69.2 and 0.82 respectively) at the $14^{\text {th }}$ DPV then declined at the $21^{\text {st }}$ DPV (66.2 and 0.8 respectively) while the inactivated FMD Montanide 201 oil (Formula-3) revealed increasing in the mean value of phagocytic \% and Phagocytic index from (23.3 and 0.10 respectively) at the day 1 to reach its maximum value (70.4 and 0.84 respectively) at the $14^{\text {th }} \mathrm{DPV}$ then declined at the $21^{\text {st }}$ DPV (66.3, 0.81respectively) , Finally sheep vaccinated with inactivated FMD ISA 201 oil with aluminum hydroxide gel vaccine (Formula-4) showed phagocytic \% and Phagocytic index increasing from (29.2 and 0.11 respectively) at the day 1 to reach its maximum value ( 92.3 and 0.99 respectively) at the $14^{\text {th }}$ DPV then declined at the $21^{\text {st }}$ 


\section{Immunomodulating Efficacy Of Different Adjuvants ......}

DPV (70.4 and 0.90 respectively), but the control sheep remain phagocytic \% and Phagocytic index around (19 to 19.5 and 0.10 to 0.13 respectively) all over the time of estimation.

Table (5) showed that the cellular immune response through estimation of interleukin-6 (IL6) of sheep to the inactivated FMD ISA 206 oil vaccine (Formula-1) revealed increasing of mean value of IL6 at day 1, 3, 7, 14, 21 and 28 DPV from (0.85) at the day 1 to reach its maximum value (3.74) at the $14^{\text {th }}$ DPV then declined at the $21^{\text {st }}$ DPV (3.42), but in sheep vaccinated with inactivated FMD 206 oil with aluminum hydroxide gel vaccine (Formula-2), showed an increase in the mean value of IL6 from (1.22) at the day 1 to reach its maximum value (3.92) at the $7^{\text {th }}$ DPV then declined at the $14^{\text {th }}$ DPV (3.72). While the inactivated FMD Montanide 201 oil (Formula-3) revealed increasing in the mean value of IL6 from (1.41) at the day 1 to reach its maximum value (4.59) at the $7^{\text {th }}$ DPV then declined at the $14^{\text {th }}$ DPV (3.96). Sheep vaccinated with inactivated FMD ISA 201 oil with aluminum hydroxide gel vaccine (Formula-4) showed increasing in the mean value of IL6 from (2.42) at the day 1 to reach its maximum value (4.73) at the $7^{\text {th }}$ DPV then declined at the $14^{\text {th }}$ DPV (4.12), While the control negative non vaccinated sheep group, the mean value of IL6 remain around (0.39 to 0.48) allover the time of estimation.

From the above results and the statistical analysis of cellular immunity, it revealed that the FMD vaccine adjuvanated with Montanide ISA oils either 201 or 206 with aluminum hydroxide gel showed a higher post vaccinal cellular immune response than that without mixing with gel and so the addition of gel has a great impact on the post vaccinal cellular immune response (Park et al., 2014). These results were in agreement with (Knudsen et al., 1979; Sharma et al., 1984) who reported that cell mediated immune response was a constitute of immune response against FMD virus, and in agreement in some points with (Knudsen et al., 1979; Mercedes et al., 1996; Elwatany et al., 1999; Sonia et al., 2010; Fakhry et al., 2012 and Mossad et al., 2014) who mentioned that the Delta optical density of lymphocyte blastogenesis assay and interleukin- 6 at day $0,3,7,14,21$ and 28 days post vaccination (DPV) showed that a significant difference between vaccinated and control groups started at $3^{\text {rd }}$ DPV and increased gradually till $21^{\text {st }} \mathrm{DPV}$ using trivalent FMD Montanide inactivated vaccine.
Evaluation of the humeral immune response against FMDV serotype (O) antibody titer in vaccinated sheep with different prepared oil adjuvant vaccine formulae were done using SNT and ELISA data (Table-6) showed differences in the onset, intensity and duration of the FMD serotype $\mathrm{O}$ antibodies. Concerning the onset of protective antibody titer, it is clear that inactivated FMD ISA 206 oil vaccine induced titers of $\left(1.65 \pm 0.070^{\mathrm{a}}\right.$ by SNT and 1.92 $\pm 0.090^{\mathrm{a}} \quad \log _{10}$ by ELISA) in the $3^{\text {rd }}$ WPV and inactivated FMD ISA 206 oil with aluminum hydroxide gel vaccine induced titers of $\left(1.54 \pm 0.082^{\mathrm{a}}\right.$ by SNT and $1.81 \pm 0.084^{\mathrm{a}} \log _{10}$ by ELISA) in the $2^{\text {nd }}$ WPV while inactivated FMD ISA 201 oil vaccine showed earlier immune response in the $2^{\text {nd }}$ WPV $\left(1.62 \pm 0.120^{\mathrm{a}}\right.$ by SNT, $1.8 \pm 0.090^{\mathrm{a}} \log _{10}$ by ELISA). On the other side, the inactivated FMD ISA 201 oil with aluminum hydroxide gel vaccine induced protective type (O) antibody titer $\left(1.73 \pm 0.047^{\mathrm{a}}\right.$ by SNT and $1.92 \pm 0.049^{\mathrm{a}} \log _{10}$ by ELISA) in the $2^{\text {nd }}$ WPV.

It is clear that peak of the protective antibody titers induced by the inactivated FMD ISA 206 oil vaccine $\left(2.76 \pm 0.030^{\mathrm{c}}\right.$ by SNT and $2.99 \pm 0.030^{\mathrm{c}} \log _{10}$ by ELISA) appeared in the $14^{\text {th }} \mathrm{WPV}$ and by the inactivated FMD ISA 206 oil with aluminum hydroxide gel vaccine $\left(2.92 \pm 0.006^{\mathrm{a}}\right.$ as SNT and $3.13 \pm 0.003^{\mathrm{a}} \log _{10}$ as ELISA) in the $10^{\text {th }} \mathrm{WPV}$ while the inactivated FMD ISA 201 oil vaccine induced the peak of antibody titers in the $10^{\text {th }}$ WPV $\left(3.1 \pm 0.050^{\mathrm{b}}\right.$ by SNT, $3.23 \pm 0.050^{\mathrm{b}} \log _{10}$ by ELISA). On the other side, the inactivated FMD ISA 201 oil with aluminum hydroxide gel vaccine induced peak protective antibody titers $\left(3.31 \pm 0.067^{\mathrm{a}, \mathrm{b}}\right.$ by SNT and $3.57 \pm 0.075^{\mathrm{a}, \mathrm{b}}$ $\log _{10}$ by ELISA) in the $8^{\text {th }}$ WPV.

Regarding the duration of the protective type (O) antibody titers, it is clear that inactivated FMD ISA 206 oil vaccine showed protective titers of $\left(1.52 \pm 0.120^{\mathrm{b}, \mathrm{c}}\right.$ by SNT and $1.84 \pm 0.118^{\mathrm{b}, \mathrm{c}} \quad \log _{10}$ by ELISA) up to the $32^{\text {th }}$ WPV and also those induced by the inactivated FMD ISA 206 oil with aluminum hydroxide gel vaccine $\left(1.52 \pm 0.095^{\mathrm{a}}\right.$ as SNT and $1.84 \pm 0.103^{\mathrm{a}} \log _{10}$ as ELISA) up to the $32^{\text {th }} \mathrm{WPV}$ while inactivated FMD ISA 201 oil vaccine showed later protective antibody titers in the $36^{\text {th }}$ WPV $\left(1.65 \pm 0.080^{\mathrm{b}}\right.$ by SNT and $1.91 \pm 0.086^{\mathrm{b}} \log _{10}$ by ELISA). Also, it was noticed that the protective type $(\mathrm{O})$ antibody titers induced by inactivated FMD ISA 201 oil with aluminum hydroxide gel vaccine $\left(1.65 \pm 0.047^{\mathrm{a}, \mathrm{b}}\right.$ by 
SNT and $1.92 \pm 0.043^{\mathrm{b}} \log _{10}$ by ELISA) up to the $36^{\text {th }}$ WPV.

From the above results and the statistical analysis of humeral antibody titers against FMDV serotype $(\mathrm{O})$ revealed that the Montanide oils 201 with aluminum hydroxide gel is the best vaccine formula then Montanide oils 201 induced earlier, long lasting immunity then Montanide oils 206 with aluminum hydroxide gel and finally Montanide oils 206.These results came in parallel to those described by (Dong $\boldsymbol{e t}$ al., 2013) who mentioned that the ELISA antibodies against FMDV type $\mathrm{O}$ were compared as induced by Montanide oils 201and 206 showing that the antibody titer induced by oil 201-vaccine were higher than those induced by the oil 206 vaccine on $3 \mathrm{dpv}, 7 \mathrm{dpv}, 14 \mathrm{dpv}$, $21 \mathrm{dpv}$ and $28 \mathrm{dpv}$. This means that the immune stimulating effect of 201 oil is better than that of 206vaccine.

Regarding to FMDV serotype (A) antibody titers induced in vaccinated sheep the different prepared vaccine formulae are determined by using SNT and ELISA data (Table-7) showed differences in the onset, intensity and duration of the FMD serotype A antibodies. Concerning the onset of protective antibody titer, it is clear that inactivated FMD ISA 206 oil vaccine induced titers of $\left(1.52 \pm 0.060^{\mathrm{a}}\right.$ by SNT and $1.82 \pm 0.050^{\mathrm{b}} \log _{10}$ by ELISA) in the $3^{\text {rd }}$ WPV and inactivated FMD ISA 206 oil with aluminum hydroxide gel vaccine induced titers of $\left(1.52 \pm 0.080^{\mathrm{a}}\right.$ by SNT and $1.8 \pm 0.082^{\mathrm{a}} \log _{10}$ by ELISA) in the $2^{\text {nd }} \mathrm{WPV}$ while inactivated FMD ISA 201 oil vaccine showed earlier immune response in the $2^{\text {nd }} W P V\left(1.59 \pm 0.100^{\mathrm{a}}\right.$ by SNT, $1.84 \pm 0.022^{a} \log _{10}$ by ELISA). On the other side the inactivated FMD ISA 201 oil with aluminum hydroxide gel vaccine induced protective type (A) antibody titer $\left(1.71 \pm 0.035^{\mathrm{a}}\right.$ by SNT and $1.82 \pm 0.039^{\mathrm{a}}$ $\log _{10}$ by ELISA) in the $2^{\text {nd }}$ WPV.

It is clear that peak of the protective antibody titers induced by the inactivated FMD ISA 206 oil vaccine $\left(2.76 \pm 0.006^{\mathrm{a}}\right.$ by SNT and $3.01 \pm 0.110^{\mathrm{a}} \log _{10}$ by ELISA) appeared in the $14^{\text {th }} \mathrm{WPV}$ and by the inactivated FMD ISA 206 oil with aluminum hydroxide gel vaccine $\left(2.91 \pm 0.006^{\mathrm{a}}\right.$ as $\mathrm{SNT}$ and $3.17 \pm 0.008^{\mathrm{a}} \log _{10}$ as ELISA) in the $10^{\text {th }} \mathrm{WPV}$ while the inactivated FMD ISA 201 oil vaccine induced the peak of antibody titers in the $10^{\text {th }}$ WPV $\left(3.0 \pm 0.054^{\mathrm{b}}\right.$ by SNT, $3.27 \pm 0.060^{\mathrm{a}, \mathrm{b}} \log _{10}$ by ELISA). On the other side the inactivated FMD ISA 201 oil with aluminum hydroxide gel vaccine induced peak protective antibody titers $\left(3.24 \pm 0.108^{\mathrm{a}}\right.$ by $\mathrm{SNT}$ and $3.45 \pm 0.111^{\mathrm{a}}$ $\log _{10}$ by ELISA) in the $8^{\text {th }}$ WPV.

Regarding the duration of the protective type (A) antibody titers, it is clear that inactivated FMD ISA 206 oil vaccine showed protective titers of $\left(1.65 \pm 0.060^{c}\right.$ by SNT and $1.89 \pm 0.101^{\mathrm{a}} \quad \log _{10}$ by ELISA) up to the $32^{\text {th }}$ WPV and also those induced by the inactivated FMD ISA 206 oil with aluminum hydroxide gel vaccine $\left(1.66 \pm 0.081^{\mathrm{a}}\right.$ as $\mathrm{SNT}$ and $1.99 \pm 0.086^{\mathrm{a}} \quad \log _{10}$ as ELISA) up to the $32^{\text {th }} \mathrm{WPV}$ (WPV) while inactivated FMD ISA 201 oil vaccine showed later protective antibody titers in the $36^{\text {th }} \mathrm{WPV}$ $\left(1.73 \pm 0.083^{\mathrm{c}}\right.$ by SNT and $1.92 \pm 0.052^{\mathrm{b}} \quad \log _{10}$ by ELISA). Also, it was noticed that the protective type (A) antibody titers induced by inactivated FMD ISA 201 oil with aluminum hydroxide gel vaccine $\left(1.75 \pm 0.057^{\mathrm{b}}\right.$ by SNT and $1.95 \pm 0.069^{\mathrm{b}} \log _{10}$ by ELISA) up to the $36^{\text {th }}$ WPV. From the above results and the statistical analysis of humeral antibody titers against FMDV serotype A revealed that the Montanide oils 201 with aluminum hydroxide gel is the best vaccine formula then Montanide oils 201 induced earlier, long lasting immunity then Montanide oils 206 with aluminum hydroxide gel and finally Montanide oils 206

Demonstration of FMD type SAT2/Egypt/2012 antibody titers induced in vaccinated sheep with the prepared different oil vaccine formulae using SNT and ELISA data (Table-8) showed differences in the onset, intensity and duration of the FMD serotype SAT2/Egypt/2012 antibodies. Concerning the onset of protective antibody titer, it is clear that inactivated FMD ISA 206 oil vaccine induced titers of $\left(1.55 \pm 0.052^{\mathrm{b}}\right.$ by SNT and $1.91 \pm 0.063^{\mathrm{b}} \log _{10}$ by ELISA) in the $3^{\text {rd }}$ WPV and inactivated FMD ISA 206 oil with aluminum hydroxide gel vaccine induced titers of $\left(1.67 \pm 0.101^{\mathrm{b}}\right.$ by SNT and $1.86 \pm 0.105^{\mathrm{b}} \log _{10}$ by ELISA) in the $2^{\text {nd }}$ WPV also inactivated FMD ISA 201 oil vaccine showed earlier immune response in the $2^{\text {nd }}$ WPV $\left(1.71 \pm 0.126^{\mathrm{a}}\right.$ by SNT, $1.96 \pm 0.096^{\mathrm{a}} \log _{10}$ by ELISA). On the other side, the inactivated FMD ISA 201 oil with aluminum hydroxide gel vaccine induced protective type SAT2/Egypt/2012 antibody titer $\left(1.87 \pm 0.043^{\mathrm{a}}\right.$ by SNT and $2.20 \pm 0.046^{\mathrm{a}} \log _{10}$ by ELISA) in the $2^{\text {nd }} \mathrm{WPV}$.

It is clear that peak of the protective antibody titers induced by the inactivated FMD ISA 206 oil vaccine $\left(2.71 \pm 0.003^{\mathrm{c}}\right.$ by SNT and $2.93 \pm 0.025^{\mathrm{c}} \log _{10}$ by 
ELISA) appear in the $14^{\text {th }}$ WPV and by the inactivated FMD ISA 206 oil with aluminum hydroxide gel vaccine $\left(3.01 \pm 0.072^{\mathrm{a}}\right.$ as SNT and $3.26 \pm 0.072^{\mathrm{a}} \log _{10}$ as ELISA) in the $10^{\text {th }}$ WPV also the inactivated FMD ISA 201 oil vaccine induced the peak of antibody titers in the $10^{\text {th }} \mathrm{WPV}\left(3.09 \pm 0.043^{\mathrm{b}}\right.$ by SNT, $3.34 \pm 0.043^{\mathrm{b}} \log _{10}$ by ELISA). On the other side, the inactivated FMD ISA 201 oil with aluminum hydroxide gel vaccine induced peak protective antibody titers $\left(3.33 \pm 0.092^{\mathrm{a}, \mathrm{b}}\right.$ by SNT and $3.55 \pm 0.096^{\mathrm{a}, \mathrm{b}} \log _{10}$ by ELISA) in the $10^{\text {th }}$ WPV.

Regarding the duration of the protective typeSAT2/Egypt/2012 antibody titers, it is clear that inactivated FMD ISA 206 oil vaccine showed protective titers of $\left(1.65 \pm 0.009^{\mathrm{b}}\right.$ by SNT and $1.92 \pm 0.021^{\mathrm{b}} \log _{10}$ by ELISA) up to the $32^{\text {th }}$ WPV and also those induced by the inactivated FMD ISA 206 oil with aluminum hydroxide gel vaccine $\left(1.65 \pm 0.023^{\mathrm{a}}\right.$ as SNT and $1.92 \pm 0.029^{\text {a }} \log _{10}$ as ELISA) up to the $32^{\text {th }}$ WPV while inactivated FMD ISA 201 oil vaccine showed later protective antibody titers in the $36^{\text {th }}$ WPV $\left(1.68 \pm 0.062^{\mathrm{c}}\right.$ by SNT and $1.97 \pm 0.069^{\mathrm{a}} \log _{10}$ by ELISA).It was noticed that the protective type SAT2/Egypt/2012 antibody titers induced by inactivated FMD ISA 201 oil with aluminum hydroxide gel vaccine $\left(1.73 \pm 0.121^{\mathrm{a}, \mathrm{b}}\right.$ by $\mathrm{SNT}$ and $1.99 \pm 0.130^{\mathrm{a}, \mathrm{b}} \log _{10}$ by ELISA) up to the $36^{\text {th }} \mathrm{WPV}$. From the above results and the statistical analysis of humeral antibody titers against FMDV serotype SAT2/Egypt/2012 revealed that the Montanide oils 201 with aluminum hydroxide gel is the best vaccine formula then Montanide oils 201 induced earlier, long lasting immunity then Montanide oils 206 with aluminum hydroxide gel and finally Montanide oils 206.

Demonstration of FMD type SAT2/Egypt/2018 antibody titers induced in vaccinated sheep with the prepared different oil vaccine formulae by using SNT and ELISA data (Table-9) showed differences in the onset, intensity and duration of the FMD serotype SAT2/Egypt/2018 antibodies. Concerning the onset of protective antibody titer, it is clear that inactivated FMD ISA 206 oil vaccine induced titers of $\left(1.55 \pm 0.056^{\mathrm{a}, \mathrm{b}}\right.$ by SNT and $1.92 \pm 0.087^{\mathrm{a}} \log _{10}$ by ELISA) in the $3^{\text {rd }}$ WPV and inactivated FMD ISA 206 oil with aluminum hydroxide gel vaccine induced titers of $\left(1.62 \pm 0.087^{\mathrm{b}}\right.$ by SNT and $1.98 \pm 0.139^{\mathrm{b}} \log _{10}$ by ELISA) in the $2^{\text {nd }}$ WPV also inactivated FMD ISA 201 oil vaccine showed earlier immune response in the $2^{\text {nd }}$
WPV $\left(1.68 \pm 0.088^{\mathrm{a}}\right.$ by SNT, $2.01 \pm 0.06^{\mathrm{b}} \log _{10}$ by ELISA). On the other side, the inactivated FMD ISA 201 oil with aluminum hydroxide gel vaccine induced protective type SAT2/Egypt/2018 antibody titer $\left(1.71 \pm 0.010^{\mathrm{a}}\right.$ by SNT and $2.2 \pm 0.019^{\mathrm{a}} \log _{10}$ by ELISA) in the $2^{\text {nd }} \mathrm{WPV}$.

It is clear that peak of the protective antibody titers induced by the inactivated FMD ISA 206 oil vaccine $\left(2.54 \pm 0.056^{\mathrm{a}}\right.$ by SNT and $2.8 \pm 0.144^{\mathrm{a}} \log _{10}$ by ELISA) appear in the $14^{\text {th }} \mathrm{WPV}$ and by the inactivated FMD ISA 206 oil with aluminum hydroxide gel vaccine $\left(2.94 \pm 0.04^{\mathrm{b}}\right.$ as SNT and $3.17 \pm 0.050^{\mathrm{b}} \log _{10}$ as ELISA) in the $10^{\text {th }} \mathrm{WPV}$ also the inactivated FMD ISA 201 oil vaccine induced the peak of antibody titers in the $10^{\text {th }}$ WPV $\left(3.01 \pm 0.102^{\mathrm{b}}\right.$ by SNT, $3.27 \pm 0.114^{\mathrm{a}} \log _{10}$ by ELISA). On the other side the inactivated FMD ISA 201 oil with aluminum hydroxide gel vaccine induced peak protective antibody titers $\left(3.36 \pm 0.097^{\mathrm{a}}\right.$ by SNT and $3.58 \pm 0.139^{\mathrm{a}} \log _{10}$ by ELISA) in the $8^{\text {th }} \mathrm{WPV}$.

Regarding the duration of the protective typeSAT2/Egypt/2018 antibody titers, it is clear that inactivated FMD ISA 206 oil vaccine showed protective titers of $\left(1.51 \pm 0.102^{\mathrm{a}}\right.$ by $\mathrm{SNT}$ and $1.81 \pm 0.110^{\mathrm{a}, \mathrm{b}} \log _{10}$ by ELISA) up to the $32^{\text {th }}$ WPV and also those induced by the inactivated FMD ISA 206 oil with aluminum hydroxide gel vaccine $\left(1.76 \pm 0.141^{\mathrm{a}, \mathrm{b}}\right.$ as SNT and $1.87 \pm 0.010^{\mathrm{a}} \log _{10}$ as ELISA) up to the $32^{\text {th }}$ WPV while inactivated FMD ISA 201 oil vaccine showed later protective antibody titers in the $36^{\text {th }} \mathrm{WPV}$ $\left(1.71 \pm 0.010^{\mathrm{a}, \mathrm{b}}\right.$ by SNT and $2.04 \pm 0.062^{\mathrm{b}, \mathrm{c}} \log _{10}$ by ELISA).It was noticed that the protective type A antibody titers induced by inactivated FMD ISA 201 oil with aluminum hydroxide gel vaccine $\left(1.86 \pm 0.048^{\mathrm{b}}\right.$ by SNT and $2.18 \pm 0.141^{\mathrm{c}} \log _{10}$ by ELISA) up to the $36^{\text {th }}$ WPV. From the above results and the statistical analysis of humeral immunity, it revealed that the Montanide oils 201 with aluminum hydroxide gel is the best vaccine formula then Montanide oils 201 induced earlier, long lasting immunity then Montanide oils 206 with aluminum hydroxide gel and finally Montanide oils 206.

Our results came in parallel with the result obtained by (EL-Sayed et al., 2015) who indicated that vaccines emulsified using Montanide ISA 201 adjuvant elicited a protective humoral immune response from the $2^{\text {nd }}$ WPV for ISA 201 oil by SNT and ELISA titers of $\left(1.62 \pm 0.047^{\mathrm{a}}\right.$ and $\left.1.8 \pm 0.049^{\mathrm{a}}\right) ;\left(1.59 \pm 0.076^{\mathrm{a}}\right.$ and $\left.1.836 \pm 0.077^{\mathrm{a}}\right)$ and $\left(1.71 \pm 0.06^{\mathrm{b}}\right.$ and $\left.1.96 \pm 0.074^{\mathrm{b}}\right)$ by SNT and ELISA for serotypes O, A, SAT2, 
respectively and ISA 206 showed antibody titer by SNT and ELISA of $\left(1.5 \pm 0.082^{\mathrm{a}}\right.$ and $\left.1.84 \pm 0.084^{\mathrm{a}}\right)$; $\left(1.56 \pm 0.037^{\mathrm{a}}\right.$ and $\left.1.818 \pm 0.052^{\mathrm{a}}\right)$ and $\left(1.5 \pm 0.106^{\mathrm{a}, \mathrm{b}}\right.$ and $1.81 \pm 0.104^{\mathrm{a}, \mathrm{b}}$ ) for FMD virus serotypes $\mathrm{O}$, A and SAT2, respectively. And also came in parallel with (Wisniewski et al., 1972) they explained that the SNT measures those antibodies which neutralize the infectivity of FMD virion. The peak of antibody titre in all groups at 10-12 weeks post vaccination and continues with protective level till $32^{\text {th }}$ WPV. Our results also were consistent with the statement of (Hamblin et al., 1986) who explained that the SNT measures those antibodies which neutralize the infectivity of FMD virion, while ELISA probably measure all classes of antibodies even those produced against incomplete and non-infectious virus.

The selection of adjuvants in FMD vaccine formulation is important for both early and longlasting immunity and protection (Park et al., 2014). The aluminum hydroxide gel is the most commonly used adjuvant in commercial vaccines (Rimaniol and Gras, 2004). A previous report showed that aluminum hydroxide gel induces Th2-type responses in animal models, facilitating the dissemination of antibodies from the injected region (Gupta et al., 1995 and Brewer et al., 1996). In addition, the aluminum hydroxide gel was shown to play an important role in memory responses by inducing the differentiation of macro- phages. Gel-adjuvanated FMD vaccines are currently used only in cattle, because they offer only a short period of immunity, making them unsuitable for use in pigs (Park, 2013). Moreover, the immune responses in sheep and goats are poorer than those of oil-based vaccines (Patil $\boldsymbol{e t}$ al., 2002 a,b). The combined components of oil and aluminum hydroxide gel have been used to protect against rabies in bovines (Reddy and Srinivasan, 1996).

\section{CONCLUSIONS}

FMD polyvalent vaccines prepared with ISA 201 with aluminum hydroxide gel could be considered the best vaccines inducing both cellular and humeral immunity then vaccine formulation prepared with ISA 201 then ISA 206 with aluminum hydroxide gel and the lastly vaccines prepared with ISA 206 alone. Also we can conclude that aluminum hydroxide gel improves the effects of ISA adjuvants.

\section{REFERENCES}

ABD EL- RAHMAN, A. O., FARAG, M. A., SAMIRA EL- KILANY, EMAN, M. A., MANAL ABO EL YAZED AND ZEIDAN, S. 2006. Isolation and identification of FMDV during an outbreak of 2006 in Egypt. Kafr El- Sheikh Vet. Med. J.; 4(1).

ABD EL-RHMAN, M.M., ABO EL-HASSAN, D.G. AND SALEM, S.A.H. 2015. Sero survey on current status of foot and mouth disease in some Egyptian governorates, 2013-2015. Egypt. J. Virol., 12(2. 48-56.

ABD EL-RHMAN MM, ABO EL-HASSAN DG, AWAD WS AND SALEM SAH 2020. Serological evaluation for the current epidemic situation of foot and mouth disease among cattle and buffaloes in Egypt, Veterinary World, 13(1. 1-9.

ANTLEY, P.P. AND HAZEN, K.C. 1988. Role of yeast cell growth temperature on Candida albicans virulence in mice. Immunology Journal, 56: 2884-2890.

AUCOUTURIER, J., DUPUIS, L. AND GANNE, V. 2001. Adjuvants designed for veterinary and human vaccines. Vaccine.19:2666-2672.

BARNETT, P., PULLEN, L. WILliAMS, L. AND DOEL, T.R. 1996. Assessment of Montanide ISA 25 and ISA 206, two commercially available oil adjuvant. Vaccine, 14(13.1187-1198.

BARNETT, P.V., COX S.J., AGGARWAL, N., GERBER, H. AND MCCULLOUGH, K.C. 2002. Further studies on the early responses of pigs following immunization with high potency foot and mouth disease vaccine. Vaccine, 19: 3197-208.

BARNETT,P.V.; STATHAM, R.J.; VOSLOO, W. AND HAYDON, D.T. 2003. "Foot-and-mouth disease vaccine potency testing: determination and statistical validation of a model using a serological approach." Vaccine, 21(23.3240-8.

BREWER,J.M., CONACHER,M., SATOSKAR,A., BLUETHMANN,H. AND ALEXANDER,J. 1996. In interleukin-4-deficient mice, alum not only generates $\mathrm{T}$ helper 1 responses equivalent to Freund's complete adjuvant, but continues to induce $\mathrm{T}$ helper 2 cytokine production. Eur. J. Immunol. 26, 2062-2066.

CLOETE,M., DUNGU, B., VAN STADEN, L., ISMAILCASSIM, N. AND VOSLOO, W.2008. Evaluation of different adjuvants for foot-and-mouth disease vaccine containing all the SAT serotypes. Onderstepoort J Vet Res. ;75:17-31.

CODE OF FEDERAL REGULATION OF USA. 2019. Animal and Animal Products 9\2019. Office of the Federal Register National Archives and Record Administration.

DAOUD HM, IBRAHIM EE, EL-DIN WMG AND HASSANIN AIH 2013. Preparation of Foot and Mouth Disease trivalent vaccine type A, O, SAT2 and 
determination of the Guinea pig protective dose 50 (GPPD ), Veterinary World 6(11.844-851.

DARA P., KALAIVANANA R., SIED N., MAMO B., KISHORE S., SURYANARAYA V.V. AND KONDABATTULA G. 2013. Montanide ISA201 adjuvanted FMD vaccine induces improvedimmune responses and protection in cattle. Vaccine,31:33273332.

DEPA, P.M., DIMRI, U., SHARMA, M.C. AND TIWARI, R. 2012. Update on epidemiology and control of foot and mouth disease - A menace to international trade and global animal enterprise. Vet. World, 5(11. 694-704.

DONG LI, CHUNXUE ZHOU, DALIANG SHE, PINGHUA LI, PU SUN, XINGWEN BAI, YINGLI CHEN, BAOXIA XIE AND ZAIXIN LIU 2013. The comparison of the efficacy of swine FMD vaccine emulsified with oil adjuvant of ISA 201 VG or ISA 206 VG, Journal of Biosciences and Medicines, 1, 22-25, http://dx.doi.org/10.4236/jbm..13005

EL-BAGOURY, G.F., EL-HABBAA, A. S., GAMIL, M.A. AND FAWZY, H.G. 2014. Evaluation of an inactivated combined oil vaccine prepared for foot and mouth disease and bovine ephemeral fever. Benha Vet. Med. J., 27(1. 221-231.

EL-NAGGAR, H. 2012. Preparation of inactivated lyophilized NDV vaccine, M.V.Sc in Veterinary Science (Virology). Cairo University.

EL-SAYED E. IBRAHIM, WAEL MOSSAD GAMAL, AMR ISMAIL HASSAN, SAFY EL-DINMAHDY, AKRAM ZAKRIA HEGAZY AND MAGDY MAHMOUD ABDEL-ATTY 2015. Comparative study on the immunopotentiator effect of ISA 201, ISA 61, ISA 50, ISA206 used in trivalent foot and mouth disease vaccine .Veterinary World, EISSN:22310916, P.(1189-1198)

EL-WATANY, H., SHAWKY, M., RHSHDY, O.H. AND EL- KELANY, S. 1999. Relationship between cellular and humoral immunity responses in animal vaccinated with FMD vaccine. Zigzag Veterinary Medical Journal, 27: 137-143.

FAKHRY, H.M., RIZK, S.A., ABU-ELNAGA, H.I., DEGHAIDY, W., TALAAT, A.A. AND HEGAZI, A.Z. 2012. Field application of bivalent foot and mouth disease vaccine adjuvanted with Montanide ISA $(25,50,206)$ and IMS (1113-3015) as an alternative to aluminum hydroxide gel. Egypt. J. Virol., 9(1. 123-136

FArAg, M.A., Aggour, M. A. AND DAOUd, A.M. 2005. ELISA as a rapid method for detecting the correlation between the field isolates of FMD and the current used vaccine strain in Egypt.Vet. Med. J. Giza, Vol. 53 no. 4: 949- 955.

FERREIRA, M.E.V. 1976. Prubade microneutralization poraestudies de anticueropos de la fibre aftosa. $13^{\text {th }}$ Centropanamericano Fiebre Aftosa, (21/22. 17-24
FOOD AND AGRICULTURE ORGANIZATION. 2011. The Progressive Control Pathway for FMD Control (PCP-FMD. Principles, Stage Descriptions and Standards. Available from: http:// www.fao.org/ag/againfo/commissions/docs/pcp/pcp260 12011.pdf. Last accessed on 20-12-2019.

FRANKI, R.I.B., FAUQUET, C.M., KNUDSON, D.L. AND BROWN, F. 1991. Classification and nomenclature of viruses. 5th Report of International Communication on Taxonomy of Viruses, suppl. 2.

GUPTA,R.K., ROST,B.E., RELYVELD,E. AND SIBER,G.R. 1995. Adjuvant properties of aluminum and calcium compounds, Pharm. Biotechnol. 6, 229248.

HAMBLIN,C., BARNETT,I.T.R. AND CROWTHER, J.R 1986. New Enzyme-Linked ImmunoSorbent Assay (ELISA) for the detection of antibodies against FMD virus. $\Pi$ Application. Journal of Immunological Methods, 93: 123-129.

HARMON, B.G. AND GLISSON, J.R. 1989. In vitro microbial activity of avian peritoneal macrophages. Avian Disease Journal, 33: 177-181.

HUSSEIN, H.A. 1989. Immunosuppressive effect of MDV. B.V.SC, Virology Vet. Thesis, Cairo Univ.

ISMAIL, A.H., EL-MAHDY, S.A., MOSSAD, W.G., ABD EL-KRIM, A.S., ABOU EL-YAZID, M. AND ALI, S.M 2013. Optimization of the inactivation process of FMD virus serotype SAT-2 by binary ethyleneimine (BEI). J. Vet, Adv., 3(3. 117-124.

JULEFF N. D., MAREE, F. F., WATERS, R., BENGIS, R. G. AND CHARLESTON B. 2012. The importance of FMDV localization in lymphoid tissue. Veterinary Immunology and Immuno- pathology, 148:145-148.

KNUDSEN, R.C., GROOCOCK, C.M. AND AADERSON, A.A. 1979. Immunity to foot-and-mouth disease virus in guinea pigs: clinical and immune responses. Infection and Immunity 24: 787-792.

LEE, L.F. 1984. Proliferative response of chicken B and T lymphocyte to mitogen. Veterinary Medicine Journal, 15: 44-52.

LOMBARD, M., PASTORET, P.P. AND MOULIN, A.M. 2007. A brief of vaccines and vaccination. Rev. Sci. Tech., 26(1. 29-48.

LONGJAM, N., DEB, R., SARMAH, A.K., TAYO, T., AWACHAT, V.B. AND SAXENA, V.K. 2011. A brief review on diagnosis of foot and-mouth disease of livestock: Conventional to molecular tools. Vet. Med. Int.,: 905768.

LUCY, F.L. 1977. Chicken Lymphocyte stimulation by mitogenes. A microassay with whole blood cultures. Avian Disease, 22: 296-307.

MAYER, S., FALKENRODT, A. AND TONGIO, M.M. 1974. Anomalous reactivity of sera containing cold lymphocytotoxins with chronic leukemic lymphocytes. Tissue Antigens, 4: 266-270. 
MERCEDES G. V.,TIMOTHY D., TREVOR C., MARTIN R. AND R. MICHAEL E. P. 1996. Recognition of foot-and-mouth disease virus and its capsid protein VP1 by bovine peripheral $\mathrm{T}$ lymphocytes.Journal of General Virology, 77, 727-735.

MOSSAD W. GAMAL EL-DIN, EHAB EL-SAYED IBRAHIM, HIND DAOUD AND SAMIR MOHAMED ALI 2014. Humeral and cellular immune response of Egyptian trivalent foot and mouth disease oil vaccine in sheep. Res. Opin. Anim. Vet. Sci., 4(4. 178-185.

NADER M. SOBHY, SUNIL K. MOR, MOHAMMED E.M. MOHAMMED, IMAN M. BASTAWECY, HIAM M. FAKHRY, AND SAGAR M. GOYAL 2014. Phylogenetic analysis of Egyptian foot and mouth disease virus endemic strains in 2013. $5^{\text {th }}$ International Conference of Virology , Egyptian J. Virol.,Vol. 11 (1) 49-59.

OIE WORLD ORGANISATION FOR ANIMAL HEALTH .2017. Manual of diagnostic tests and vaccines for terrestrial animals, OIE, Paris. Available at:www.oie.int/en/international-standardsetting/ terrestrial-manual/access-online/ (accessed on 4 August 2018)

ORSEL,K.;DEJONG,M.C.;BOUMA,A.;STEGEMAN,J. A.ANDDEKKER,A.2007. Foot and mouth disease virus transmission among vaccinated pigs after exposure to virus shedding pigs. Vaccine 2 21;25(34.6381-91.

PARK,J.H.2013. Requirements for improved vaccines against foot-and-mouth disease epidemics. Clin. Exp. Vaccine Res. 2, 8-18.

PARK,M.E., LEE,S.Y., KIM,R.H., KO, M.K., LEE,K.N., KIM,S.M. ET AL.2014. Enhanced immune responses of foot-and-mouth disease vaccine using new oil/gel adjuvant mixtures in pigs and goats. Vaccine, 32, 1882-1889.

PARK MIN-EUN, SEO-YONG LEE, RAE-HYUNG KIM, MI-KYEONG KO, JEONG-NAM PARK, KWANG-NYEONG LEE, SU-MI KIM, JOOHYUNG CHOI, SU-HWA YOU, BYOUNGHAN KIM, JONG-SOO LEE B AND JONG-HYEON PARK 2016. Altered adjuvant of foot-and-mouth disease vaccine improves immune response and protection from virus challenge. Trials in Vaccinology 5, 97-104.

PATIL,P.K., BAYRY,J., RAMAKRISHNA,C., HUGAR, B., L.D. MISRA,L.D. AND NATARAJAN,C. 2002a. Immune responses of goats against foot-and-mouth disease quadrivalent vaccine: comparison of double oil emulsion and aluminium hydroxide gel vaccines in eliciting immunity, Vaccine 20, 2781-2789.

PATIL,P.K., BAYRY,J., RAMAKRISHNA,C., HUGAR,B., MISRA,L.D. AND PRABHUDAS,K., 2002b. Immune responses of sheep to quadrivalent double emulsion foot-and-mouth disease vaccines: rate of development of immunity and variations among other ruminants, J. Clin. Microbiol. 40 ,4367-4371.

PATON, D.J., SUMPTION, K.J. AND CHARLESTON, B. 2009. Options for control of foot and-mouth disease: knowledge, capability and policy. Philosophical Transactions of the Royal Society Biological Science B, 364: 2657-2667.

PATTNAIK, B., SUBRAMANIAM, S., SANYAL, A., MOHAPATRA, J.K., DASH, B.B. AND RANJAN, R. 2012. Foot and mouth disease; global status and future road map for control and prevention in India. Agric. Res., 1(2. 132-147.

RANDALL, R., BINN, L.N. AND HARRISON, V.R. (1964. Immunization against Rift Valley fever virus. Studies on the immunogenicity of lyophilized formalin inactivated vaccine. J. Immunol., 92: 293-299.

REDDY,G.S. AND SRINIVASAN,V.A. 1996. Performance of aluminium hydroxide gel and oil adjuvant rabies vaccines in bovines. Zentralbl Bakteriol, 286, 523-526.

RICHARDSON, M.D. AND SMITH, H. 1981. Resistance of virulent and attenuated strains of Candida albicans to intracellular killing by human and mouse phagocytes. Journal of Infectious Disease, 144: 557565.

RIMANIOL,A.C., AND GRAS,G. 2004. Aluminum hydroxide adjuvant induces macrophage differentiation towards a specialized antigen-presenting cell type, Vaccine, 13 (22), 3127-3135.

RODRIGUEZ, L.L. AND GRUBMAN, M.J.2009. Foot and mouth disease virus vaccines. Vaccine, 27 Suppl 4: D90-4.

SATYA, P. 2009. Vaccination against foot-and-mouth disease virus: Strategies and effectiveness. Expert Rev. Vaccines, 8(3. 347-365.

SÉBASTIEN DEVILLE, JULIETTE BEN AROUS, FRANÇOIS BERTRAND AND LAURENT DUPUIS 2013. MontanideTM adjuvants for stimulation of cellular immune response in FMD vaccines Tech Bull. Paris: Seppic.

SHABANA, W. 2014. Preparation of combined oil vaccine against foot and mouth disease and rift valley fever in sheep. PhD. Thesis, Virology Department, Faculty of Veterinary Medicine, Cairo University, Egypt.

SHARMA, M.C., PATHAK, M.N. HUNG, M.N., NHI D.L. AND VUC, N.V. 1984. Report on the out break of foot and mouth disease in buffaloes in the southern part of Vietnam. Veterinary Viral Diseases : 302-305.

SHAWKY M., ABD EL-ATY M., HIAM. M. FAKRY, HIND M. DAOUD, EHAB EL-SAYED I., WAEL MOSSAD G., SONIA A. RIZK, ABU-ELNAGA H., MOHAMED A. A., ABD EL-KREEM A. AND FAROUK E. M. 2013. Isolation and Molecular Characterization of Foot and Mouth Disease SAT2 
Virus during Outbreak 2012 in Egypt . J Vet Adv, 3(2. 60-68.

SLATER, T.F., SAWYER, B. AND STRÄULI, U. (1963. Studies on succinate-tetrazolium reductase system: III. Points of coupling of four different tetrazolium salts. Biochemical biophysical Acta, 77: 383-393.

SOBHY, N.M., MOR, S.K., MOHAMMED, M.E.M., BASTAWECY, I.M., FAKHRY, H.M., YOUSSEF, C.R.B. AND GOYAL, S.M. 2014. Phylogenetic analysis of Egyptian foot and mouth disease virus endemic strains. J. Am. Sci., 10(9. 133-138.

SOLTAN, M.A., NEGMALDIN, A.H., EL-DIASTY, M.M., MANSOUR, S.M.G., ELBADRY, M.A. AND WILKES, R.P. 2017. Molecular characterization of circulating foot and mouth disease virus (FMDV) serotype O topotype EA-3 and serotype A (African topotype) genotype IV in Egypt, 2016. Vet. Microbiol., 208: 89-93.

SONIA,A., RIZK, HIAM, M., FAKHRY AND ABUELNAGA, H.I. 2010. Comparative study of $\mathrm{T}$ cell proliferative response in cattle vaccinated with FMD vaccine using Cell titre Aqueous one solution non radioactive assay (MTS). Zag. Vet. J. (ISSN. 11101458) Vol. 38, No. 4 pp. 188-195.

VALDAZO-GONZÁLEZ, B., KIM, J.T., SOUBEYRAND , S., WADSWORTH, J., KNOWLES, N.J., HAYDON, D. AND KING, D.P. 2015. The impact of within-herd genetic variation upon inferred transmission trees for foot-and-mouth disease virus. Infect., Genet. Evol., 32(1. 440-448.

VOLLER, A., BID WELL, D. AND BARTLEHA 1976. Micro plate enzyme immuno assay for the immuno diagnosis of virus infection. Am. Soc. For Micro.(506512).

WISNIEWSKI J., KOBUSIEWIECZ T., BARONOWSKI C., AND JANKOWSKO J., 1972. Determination of the level of immunity in cattle on the basis of neutralizing antibodies after the use of Frenkel type FMD vaccine.Medycyna Wet 28 (10.586-588.

XUAN H., LI Y., FANG, H. AND ZHENG, C. 2011. Establishment of persistent infection with foot and mouth disease virus in BHK-21 cells. Virol. J., 8: 169.

How to cite this article:

El-Sayed, E. I. ; Mossad, W.G.;Hassanin A. I. and Shabana, W. 2020. Immunomodulating Efficacy of Different Adjuvants In Formulation of Foot and Mouth Disease Vaccine Relative to Its Immunogenicity. Journal of Applied Veterinary Sciences, 5(3): 14 - 30.

DOI:HTTPS://DX.DOI.ORG/10.21608/JAVS.2020.98318 